\title{
Auditory processing following infantile spasms: an event-related potential (ERP) study
}

\author{
Tangunu Fosi PhD MRCPCH ${ }^{1,2,3}$ Klaus Werner PhD MD ${ }^{1,3}$ Stewart G Boyd MD ${ }^{2,3}$ Michelle De Haan
} $\mathrm{PhD}^{4}$ Rod C Scott PhD MRCPCH ${ }^{\mathbf{1 , 2 , 3 , 5}}$ Brian G Neville FRCP

Affiliations:
1) Young Epilepsy, Surrey UK;
2) Great Ormond Street Hospital for Children NHS Trust, London UK;
3) Neurosciences Unit, UCL Institute of Child Health, London UK
4) Centre for developmental cognitive neurosciences, UCL Institute of Child Health, London UK
5) Department of Neurological Sciences, University of Vermont, USA

Address correspondence to: Dr Tangunu Fosi, Neurosciences Unit, UCL Institute of Child Health, 30 Guilford street, London WC1N 1EH, sejitfo@ucl.ac.uk, Telephone +44207 599 4128, Fax +44207 430 0032

\section{Short title: Cortical auditory function following infantile spasms}

Abbreviations: WS - West syndrome; uWS - WS of unknown cause (formerly 'cryptogenic' WS); ERP - Event-related potential; MMN - Mismatch Negativity

Key Words: Auditory ERP; N100; MMN; novelty P300; West syndrome; temporal lobe

Funding Source: This study was funded by Young Epilepsy (www.youngepilepsy.org.uk), a UK charity for epilepsy and undertaken at the Great Ormond Street hospital/ Institute of Child Health who receive a proportion of their funding from the Department of Health's NIHR Biomedical Research Centre funding scheme.

Conflict of Interest and Financial Disclosure: Dr. Fosi reports no disclosures; Dr. Werner reports no disclosures; Dr. Boyd reports no disclosures; Dr. De Haan reports no disclosures; Prof. Scott reports no disclosures; Prof. Neville reports no disclosures.

Conflict of Interest: The authors declare that they have no conflicts of interest.

\section{Clinical Trial Registration: None.}

Contributor's Statement: Professor Brian Neville (BN) conceived the study. Dr Stewart Boyd (SB) designed and supervised the ERP experiments. Dr Klaus Werner $(\mathrm{KW})$ performed the ERP recordings on some controls. Dr Tangunu Fosi (TF) performed the ERP recordings on all patients and the remaining controls, made ERP measurements for all subjects and performed the data analysis. Dr Michelle De Haan (MD) performed psychometric testing of the WS patients. Dr Rod C Scott (RC) and all the authors contributed intellectually to the content of this work. All authors approve the final version of this manuscript. 
Abstract word count:

Total Word count:

Figures (and number in color):

Tables:

Online Supplementary data:
204

3967

(Excluding abstract, footnotes on p16 ,Figures, Legends, Tables, and References)

$3(1)$

2

8 tables and 16 supplementary figures 


\section{ABSTRACT}

Objectives: To investigate acoustic auditory processing in patients with recent infantile spasms (IS).

Methods: Patients ( $\mathrm{n}=22 ; 12 \mathrm{~F}$; median age 8 months; range 5-11months) had normal preceding development, brain MRI, and neurometabolic testing (West syndrome of unknown cause, uWS). Controls were healthy babies ( $\mathrm{n}=22 ; 11 \mathrm{~F}$; median age 6 months; range 3-12 months). Event-related potentials (ERPs) and psychometry (Bayley scales of infant development version 2, BSID-II) took place at a month following IS remission.

Results: Following a repeated pure tone uWS patients showed less suppression of the N100 at the midtemporal electrodes to $[\mathrm{p}=0.006$ ] with a prolonged response latency $[\mathrm{p}=0.019]$. Their novelty P300 amplitude over the mid-temporal electrodes was halved $[\mathrm{p}=0.001]$. The peak of the novelty P300 to environmental broadband sounds emerged later over the left temporal lobe in patients $[\mathrm{p}=0.015]$, the lag correlating with duration of spasms $[\mathrm{r}=0.547, \mathrm{p}=0.015]$. BSID-II was lower in patients $[\mathrm{p}<$ 0.001] with no correlation to ERP.

Significance: Complex acoustic information is processed poorly following IS. This would impair language. Treatment did not reverse this phenomenon, but may have limited its severity. The data are most consistent with altered connectivity of the cortical acoustic processing areas induced by IS.

Key Words: Auditory event-related potential; novelty P300; N100; infantile spasms; West syndrome 


\section{Introduction}

Early-onset childhood epilepsies show neurological comorbidities (psychiatric, sensory-perceptual, linguistic, motor and intellectual), ${ }^{\mathbf{1}}$ whose substrates are beginning to be specified. ${ }^{2}$ Language is particularly impaired, ${ }^{3}$ even following seizure remission, ${ }^{4}$ and provides a paradigm for functional connection between the temporal and frontal lobes. ${ }^{\mathbf{5}}$ The network connection basis of poor language ability in early childhood epilepsy has been sought. However, its elucidation has been limited in part by the insensitivity of clinical measurement of language function in young children. ${ }^{6}$ Nonetheless, the behavioural and clinical assessment of severe acquired language impairment in early childhood epilepsy led to the proposal of an underlying disturbance of phonemic processing. ${ }^{7}$ A primary role for this has been contradicted however by electrophysiological evidence demonstrating preservation of appropriate cortical auditory response to phonemes. ${ }^{\mathbf{8}, 9}$ The reduced sensitivity to stress cues within the same phoneme raised the possibility of an undetected disorder of acoustic rather than linguistic auditory processing following severe childhood epilepsy. ${ }^{9}$

The normal human brain analyses acoustic structure before linguistic meaning, ${ }^{\mathbf{1 0}}$ and children's capacity for discriminating the former develops earlier than the latter. ${ }^{\mathbf{1 1}}$ Acoustic processing appears fundamental, predicting language ability. ${ }^{\mathbf{1 2}}$ Despite this, formal detailed study of acoustic processing using electrophysiological methods has not been undertaken in patients with language impairment following childhood epilepsy. This study was performed on patients with the commonest early-onset epilepsy syndrome, West syndrome (WS; incidence 1 in 3000; peak onset at 4 to 6 months). ${ }^{13}$ Following the onset of characteristic infantile spasms seizures language regresses, with subsequently slowed development. ${ }^{\mathbf{1 4}}$ Pre-linguistic acoustic 
processing at the stage of acutely regressed language was assessed using a standard technique that measures scalp voltage potential response to sounds, auditory eventrelated potentials (aERPs). ${ }^{15}$ The WS patients had normal preceding development, brain MRI, and neurometabolic testing (unknown cause or uWS). The choice of this group, roughly one-fifth of reported WS cases, ${ }^{\mathbf{1 3}}$ minimises the the effect of overt structural lesions on language and cortical function. ${ }^{\mathbf{1 6}}$ 


\section{Patients and Methods}

This cross-sectional study was approved by the joint Ethics Committee of UCL Institute of Child Health and Great Ormond Street Hospital (GOSH). Prior parental informed consent was obtained. Neonatal hearing tests (otoacoustic emissions) were normal. A paediatric cognitive psychologist used the Bayley scales of infant development, version 2 (BSID-II). ${ }^{17}$

\section{PATIENTS}

Patients were recruited prospectively over three years from consecutive cases of newly diagnosed uWS referred to GOSH. The study did not interfere with patients' normal clinical management. Video EEG, neuroimaging, and neuro-metabolic investigation of blood, urine and cerebrospinal fluid were performed in all. Brain MRI scans were reported by GOSH neuroradiologists. Treatment ${ }^{18}$ followed video-EEG confirmation of WS and parents were counseled. The regimen used for vigabatrin and steroids was:

Vigabatrin was commenced at $25 \mathrm{mg} / \mathrm{kg} / \mathrm{dose} \mathrm{PO}$ bd (50 mg/kg/day) for 24 hours, then 50 $\mathrm{mg} / \mathrm{kg} / \mathrm{dose}$ bd $(100 \mathrm{mg} / \mathrm{kg} /$ day $)$. If no clinical remission by end of $4^{\text {th }}$ day of Vigabatrin was increased to $75 \mathrm{mg} / \mathrm{kg} /$ dose bd (150 mg/kg/day).

Prednisolone was commenced at $10 \mathrm{mg}$ PO qds, increasing to $20 \mathrm{mg}$ tds if spasms continued into or reappeared in the second week. After 2 weeks of treatment Prednisolone was weaned over a further 2-3 weeks.

All patients in the study showed treatment response, defined as electroclinical remission: cessation of infantile spasms and abolition of both hypsarrhythmia and epileptiform discharges on the EEG. The duration of spasms was the time from the 
first parent-reported spasm to complete electrographic remission. The uWS patients underwent aERP recordings following remission.

\section{CONTROLS}

Age-matched controls from the local community and staff showed age-appropriate development, without familial congenital hearing impairment, chronic otitis media or other significant health problems as obtained by parental interview.

\section{DATA ACQUISITION}

Computer software ("Presentation", Neurobehavioral Networks, Albany, NY) delivered auditory stimuli via headphones. Continuous scalp EEG recordings occurred around midday during natural sleep (stage II NREM) induced by a feed, recording from $\mathrm{Ag} / \mathrm{AgCl}$ electrodes in standard 10/20 positions with a common reference $(\mathrm{CPz})$. A Neuroscan network digitized the recording at $500 \mathrm{~Hz}$, amplified (bandpass: 0.15$100 \mathrm{~Hz}$ ), and stored at 32-bit resolution (Neuroscan Inc, El Paso TX USA). Data were analyzed without applying additional off-line filtering.

\section{STIMULI AND ERP MEASUREMENT:}

The acoustic stimuli and ERP measurements have been described. ${ }^{19}$ Prior to data processing the data were re-referenced offline to linked mastoid electrodes (M1/M2). Three acoustic processing contingencies were examined: (a) pattern repetition $(1000 \mathrm{~Hz}$ stimulus); (b) frequency change detection $(2000 \mathrm{~Hz}$ frequency pure tones presented within a train of $1000 \mathrm{~Hz}$ tones); and (c) contextual novelty response to multifrequency stimulus (broadband environmental sound). These contingencies produced the obligatory N100; mismatch negativity (MMN); and novelty P300 / novelty $N c$ respectively. The processing of language is lateralised, 5 so the 
lateralisation of complex (broadband) sound processing was computed as a secondary measure of potential clinical relevance.

As a validation procedure, a brief 'counterfactual' recording was performed prior to the acoustic experiment in half the subjects of each group. The headphone was unplugged from the stimulation computer whilst remaining on the infant's ears, permitting brain activity epochs to be averaged in the absence of an auditory stimulus.

DERIVED ERP MEASURES:

\title{
Lateralized difference in the change of the novelty P300
}

\section{Amplitude}

The difference between the change in the P300 amplitude between the left and right mid-temporal electrodes $\left(\Delta^{\prime} \mathbf{L}-\mathbf{R}\right)$ was computed as follows:

$\Delta \mathbf{P 3 0 0}$ amplitude $=$

mean P300 amplitude for $1^{\text {st }} 10$ novelty presentations - mean P300 amplitude for $2^{\text {nd }} 10$ novelty presentations at $\mathrm{T} 3(\mathrm{~L})$ and $\mathrm{T} 4(\mathrm{R})$ respectively

$\Delta_{\mathrm{L}-\mathrm{R}}$ P300 amplitude $=\Delta_{\mathrm{L}} \mathrm{P300}$ amplitude $-\Delta_{\mathrm{R}} \mathrm{P300}$ amplitude

\section{Latency}

\author{
$\Delta$ P300 latency $=$ \\ mean P300 latency over $1^{\text {st }} 10$ novelty presentations - mean P300 latency over $2^{\text {nd }} 10$ novelty \\ presentations at $\mathrm{T} 3(\mathrm{~L})$ and $\mathrm{T} 4(\mathrm{R})$ respectively \\ $\Delta_{\text {L-R }}^{\prime}$ P300 latency $=\Delta_{\mathrm{L}}$ P300 latency $-\Delta_{\mathrm{R}}$ P300 latency
}

\section{Calculation of the repetition suppression of the N100}


The RS was the difference between the mean N100 amplitudes of the first 20 and the last 20 of the train of 100 iterations of the standard stimulus:

$$
\text { RS = N100 amplitude } \text { (last 20) }-\mathrm{N100} \text { amplitude } \text { (first 20) }
$$

\section{STATISTICAL ANALYSIS}

Statistical analyses were performed using SPSS version 16 (Chicago, Illinois). ANOVA results were corrected with the Greenhouse-Geisser procedure, and corrected $\mathrm{p}$ values are reported. Apparent Gaussian distributions were tested with twotailed paired t-tests with Bonferroni correction. The Mann-Whitney U test was used for non-Gaussian distributions. The relationship between treatment and the significant ERP findings was evaluated by post hoc linear regression.

\section{Results}

The uWS patients ( $\mathrm{n}=22 ; 12$ female) had onset of infantile spasms (IS) at a median age of 5 months (range 4-7 months). The cognitive profile of the patient group has been reported elsewhere, ${ }^{2}$ with all having a history of normal development followed by regression with the onset of IS. Median lag to treatment was 4 weeks (range 2-20 weeks) [Table 1]. The patients were treated with Vigabatrin $(n=20)$ or Steroids $(n=2)$, with a further 3 patients from the former group also receiving steroids. Treatment efficacy (cessation of IS with resolution of hypsarrhythmia) occurred after a median of 2 months (range 0.5 - 5months). The aERP was measured at a median of 30 days after treatment efficacy. Recording was within 14 days of treatment efficacy in 8 patients; 14-28 days in 7; 29-56 days in 6 patients; and 57-84 days in 1 patient. The control group ( $\mathrm{n}=22 ; 11$ female) were similar to the patient group for gender and age at the time of the aERP [median 6 months, range 3-12 months; Supplementary Table 1]. 


\section{BAYLEY SCORES}

Psychometric testing could not be undertaken in 9 patients due to: persistent agitation/fractiousness (6) or inability to attend (3). There was no difference between patients who had psychometric testing and those who did not with respect to ERP measures or treatment. The median (range) scores for controls / patients and the Mann-Whitney 2-tailed significance were: 100 (55-120) / 55 (55-90) for Cognition $\mathrm{p}$ $<0.001 ; 91(47-115) / 55(47-95)$ for Language $\mathrm{p}<0.001$; and $94(46-115) /$ and 55 (46-94) for Motor $\mathrm{p}<0.001$; Supplementary Table 2] The Bayley scores did not correlate with any ERP measures.

\section{EVENT-RELATED POTENTIALS}

The ERP data are summarised in Table 2, and Supplementary Tables 3-8

\section{(a) The $M M N$}

The typical MMN showing a fronto-central maximum was visible in the 'grand average' ERP (figure 1) and in the numerical data (Table 2). The MMN amplitude measured over the fronto-central $(\mathrm{Fz}, \mathrm{Cz})$ and mid-temporal $(\mathrm{T} 3, \mathrm{~T} 4)$ derivations together was larger overall in patients $[\mathrm{F}=6.523, \mathrm{p}=0.015]$. This $\mathrm{MMN}$ augmentation occurred at both sites [fronto-central $\mathrm{F}=6.798, \mathrm{p}=0.013$; midtemporal $\mathrm{F}=5.38, \mathrm{p}=0.026]$. The change was two-fold at the former but ten-fold at the latter (Supplementary Figure 1, Supplementary Tables 3-5). The MMN latency was prolonged in patients at the mid-temporal $[\mathrm{F}=18.337, \mathrm{p}=0.0001]$ but not the frontocentral electrodes $[\mathrm{F}=0.0001, \mathrm{p}=0.994]$ There was an interaction of (amplitude at T3 $\mathrm{x}$ amplitude at T4 $\mathrm{x}$ Group) over successive deviant stimuli: the MMN amplitude increased in patients but not in controls $[\mathrm{F}=3.351, \mathrm{p}=0.022]$. 


\section{(b) The novelty response}

\section{Novelty P300 peak amplitude:}

The novelty P300 topography was typical of the ' $P 3 a$ ' response to unattended stimuli.

${ }^{22}$ The frontocentral novelty P300 amplitude was reduced on average to three-quarters of the control amplitude; the mid-temporal novelty P300 amplitude was reduced to between one-third and one-half of the control amplitude (Figure 2, Supplementary figure 2). The latter was significant [fronto-central $\mathrm{F}=1.645, \mathrm{p}=0.209$; midtemporal F=12.906, $\mathrm{p}=0.001$ - Supplementary Tables 6-8].

Successive novelty stimulus presentations reduced the right mid-temporal (T4) novelty P300 amplitude in both controls and patients [significant within-subject effect $\mathrm{F}=9.571, \mathrm{p}=0.004$, with no group interaction]. The mean (SD) P300 amplitudes in $\mu \mathrm{V}$ for the $1^{\text {st }} 10 / 2^{\text {nd }} 10$ novels were: 21.7 (19) / 21.4 (18) in controls and 9.5 (10) / 6.4 (7) in patients at T3; with 25.2 (19) / 19.7 (12) in controls and 11.9 (13) / 7.1 (10) in patients at T4.This did not occur for the left mid-temporal (T3) P300 amplitude in either patients or controls [within-subject effect $\mathrm{F}=1.171, \mathrm{p}=0.286$ ] The withinsubject left-right difference in the decline of the novelty P300 was calculated $\left(\Delta^{\prime} \mathbf{L - R}\right)$. This did not differ between the two groups: $5.1 \mu \mathrm{V}$ (20) in controls and $1.76 \mu \mathrm{V}$ (12) in patients $(\mathrm{t}=-0.621, \mathrm{p}=0.539)$. The $\Delta_{\mathrm{L}-\mathrm{R}}^{\prime} \mathrm{P} 300$ amplitude in patients showed an negative correlation with treatment lag $[R=-0.448, p=0.048$ : Supplementary Figure 3].

Novelty P300 peak latency: The mean novelty P300 latency at the mid-temporal electrodes $(\mathrm{T} 3 / \mathrm{T} 4)$ was unchanged between patients and controls $[\mathrm{F}=0.008, \mathrm{p}=0.930]$. 
The latency at the mid-temporal electrodes (T3, T4) differed with repetition, however, decreasing in the control group but not in patients. [(Latency at T3 $\mathrm{x}$ Latency at $\mathrm{T} 4 \mathrm{x}$ Group) interaction: $F=7.607, p=0.013$; Supplementary Figure 4]. The mean (SD) $\Delta^{\prime}{ }_{\text {L-R P300 latency }}$ or the difference in the change of P300 latency between T3 (left temporal) and at T4 (right temporal) over the experiment was - 12ms (68) in controls and $49 \mathrm{~ms}(67)$ in patients $[\mathrm{t}=2.68$, t-test $\mathrm{p}=0.015]$. The duration of spasms correlated with $\Delta^{\prime}{ }_{\text {L-R P300 latency }}[$ Linear regression $\mathrm{R}=0.547, \mathrm{p}=0.015$, Supplementary Figure 5].

Nc Peak amplitude: No difference was found between the patient and control group for mean Nc amplitude to novels at $\mathrm{Fz}(\mathrm{p}=\mathrm{NS})$. In both patients and controls, the Nc amplitude at $\mathrm{Fz}$, increased with repetition $[\mathrm{F}=14.966, \mathrm{p}<0.0001$ within subjects $]$, and the mean change was similar $[\mathrm{F}=1.746, \mathrm{p}=0.194]$.

Nc Peak Latency: The Nc Latency at Fz was shorter in patients than in controls $[\mathrm{F}=$ 4.157, $\mathrm{p}=0.048$, Supplementary Figure 6] The mean peak latencies of the Nc response at the $\mathrm{Fz}$ electrode to the first and second four presentations of each of the four novel classes were compared, and increased in both groups $[\mathrm{F}=5.558, \mathrm{p}=0.02]$ without a significant difference between them.

\section{(c) The N100 response}

The mean N100 amplitude over 100 standard stimuli did not differ between the control and patient groups $[\mathrm{F}=0.081 ; \mathrm{p}=0.777]$. A larger amplitude occurred at $\mathrm{T} 3$ than $\mathrm{T} 4$ in both groups $[\mathrm{F}=6.556 ; \mathrm{p}=0.014]$. The groups showed different effects of standard stimulus repetition on the N100 amplitude (repetition x group interaction 
$\mathrm{F}=2.922 ; \mathrm{p}=0.002 ;$ Figure 3] The amplitude mean of the T3 and T4 N100 responses in the control group showed significant reduction over repetitions of the $1000 \mathrm{~Hz}$ stimulus $(\mathrm{R}=0.783, \mathrm{p}=0.007)$; the $\mathrm{uWS}$ group did not $(\mathrm{R}=0.236, \mathrm{p}=$ 0.511). The repetition suppression (RS) to the standard stimulus at the mid-temporal electrodes was less in patients than controls. $[\mathrm{F}=8.357, \mathrm{p}=0.006]$ The mean $(\mathrm{SD})$ for controls / patients was: $8.87(14) /-9.92(37)$ at at T3; and 10.7 (19) / -9.0 (38) at T4.

N100 peak latency: The N100 latency of the first 100 standard stimuli differed between the control and patient groups, being shorter in controls $[\mathrm{F}=5.988 ; \mathrm{p}=$ 0.019]. To identify the general trend over repetition, the first and second 50 standard stimuli were then separated. A difference in the behaviour of N100 latency over time is visible between the control and patient group. The mean (SD) N100 latency in milliseconds for the $1^{\text {st }} 50$ standards / $2^{\text {nd }} 50$ standards in controls was: 207 (25) / 183 (33) at T3 and 207 (41) / 185 (33) at T4. The corresponding values in patients are: $212(25) / 212$ (24) at T3 and 205 (29) / 202 (19) at T4. The mean N100 latency shortened from the first half to the second half bilaterally in the control group, but not in the patient group $[\mathrm{F}=5.193 ; \mathrm{p}=0.028]$.

ERPs for single subjects are shown in Supplementary Figures 7-12. The results of the validation procedure are shown in Supplementary Figures 13-16.

\section{WS TREATMENT CHOICE AND ERP}


There was no difference between patients treated with Vigabatrin or Steroids for demographics, or duration of spasms. No relationship was found on post-hoc analysis between either the current or the cumulative dose of Vigabatrin and ERP measures. 


\section{Discussion}

This study investigated acoustic processing in a severe childhood epilepsy syndrome associated with poor language. The ERP paradigm presented pure frequency and complex multifrequency (broadband) stimuli. These are processed by distinct regions of the auditory cortex (AC): the tonotopic central (core) regions respond to pure frequencies; and the peripheral (belt) regions are selectively sensitive to spectrally complex stimuli. ${ }^{20}$ The latter are downstream to the former in the connection topology of the AC, ${ }^{\mathbf{2 0}}$ and perform additional processing required to perceive sound. ${ }^{21}$ This progressive refinement of acoustic feature analysis from core to belt is thought to underlie the human aptitudes for speech and musical instrument sounds. ${ }^{22,23}$

ERPs in the expected scalp distribution and latency were elicited in controls and patients following a paradigm of pure tones and complex sounds. Pure tones produced separate responses to acoustic features (N100) and acoustic change (MMN). ${ }^{24}$ The normal asymmetry of the mid-temporal N100 response was observed in both groups, with a larger amplitude on the left (T3) than right (T4). This is thought to be a feature related to specialized processing of tone sequences. ${ }^{25}$ The preceding suggests that the ERPs in patients and controls are generated by similar processes. Of note, however, patients showed an enhanced MMN together with a failure of the normal repetitioninduced decrement of the N100. This pattern has also been reported in adult temporal lobe epilepsy (TLE). ${ }^{26}$

The MMN is a well-studied response, with a fronto-central amplitude maximum on scalp topography ('grand average' ERP in figure 1, and Table 2). It is formed of two underlying spatiotemporal components. The temporal component is earlier and 
more sensitive to primary acoustic features such as frequency or sound intensity. ${ }^{27}$ The frontal component is contingent on prior activity of the temporal component, ${ }^{28}$ although scalp distribution does not mean that the signals must arise from these anatomical lobes. The shorter latencies over the mid-temporal than the frontocentral elctrodes are consistent with this (supplementary table 3). The normal maturation of the MMN entails a reduction of amplitude. ${ }^{29}$ This process mainly concerns the temporal component in childhood and the frontal component in adulthood. ${ }^{29,30}$ The frontal and temporal region MMN amplitude and latency measurements in patients (supplementary tables 4 and 5) were both increased as compared to controls, particularly in the temporal derivations. This disproportionate change in the temporal component points to its specific alteration.

The novelty P300 response showed group difference at the mid-temporal (T3 and T4) electrodes, which overlie the superior temporal gyrus (STG). This cannot be interpreted as necessarily arising solely from the temporal lobe, as there is spatiotemporal overlap in the auditory ERP fields generated from the frontal and temporal lobes. ${ }^{\mathbf{3 1}}$ Notwithstanding, human source localization studies from scalp electromagnetic data implicate the superior temporal region as a hub of the novelty P300 response. ${ }^{32}$ The mid-temporal region was principally responsible for the reduced novelty P300 amplitude in this study. The mid-temporal amplitude in patients was reduced to between one-third and one-half of the control amplitude; whilst the frontocentral amplitude was reduced to about three-quarters. This loss of the novelty P300 ERP overlying the STG (supplementary tables 7 and 8) might be of functional significance for the following reasons. Firstly, it correlated with treatment lag. Secondly, detailed lesional studies in animals indicate that the STG, which contains 
auditory belt, supports the activation of auditory memory. ${ }^{33}$ Taken together with clinical observations, ${ }^{\mathbf{1 4}}$ the reduced novelty P300 response over the STG would point to poor activation of memory for complex sounds in uWS.

The possibility of a maturational arrest in the temporal lobe as the basis for the ERP findings was considered. Normally, ERP responses to both multifrequency and pure tone stimuli decrease in amplitude and latency in childhood. ${ }^{34,} 35$ This change coincides with a period of intense neuroanatomical remodelling, including refinement of white matter connection and synapse pruning in grey matter. ${ }^{2,35,36}$ The net effect is a smaller cortical activation field*, which determines peak latency. ${ }^{37,} 38$ The maturation of the AC follows a'centripetal' sequence, with parabelt-belt connections remodelling before belt-core connections. ${ }^{22} \mathrm{~A}$ functional consequence is that normal infants are more sensitive to multifrequency sounds. ${ }^{39,} 40$ The poorer response to multifrequency sounds than pure tone sounds in uWS makes a simple arrest of normal centripetal maturation of the auditory cortex an inadequate explanation.

There are three principal grounds for inferring that a difference in connection topology in patients prevents normal hierarchical information transfer in the AC. Firstly, both pure tones activated a larger cortical field, evidenced by greater amplitude and latency of the pure tone ERPs. Secondly, a repeated pure tone induces a decremental N100 in controls, due to post-excitatory refractoriness. ${ }^{41}$ This

\footnotetext{
* Early electrophysiological studies of voltage changes in the cortex recognized the principle of the cortical network, referring to neurons "...linked so closely in the cortex that they are always in action together." 37,38 The joint activity of these neurons produced measurable electrical potential waves over cortex, ${ }^{37}$ whose size (amplitude) was greater if the frequency of outburst by neurons in the unit increased or if a larger number of neurons were in activity (activation field). ${ }^{\mathbf{3 8}}$ The latency of the cortical potential peak was prolonged in the latter situation due to the larger number of neurons being active asynchronously. 38
} 
repetition-induced decrement of the N100 shows parallels to the normal reduction of amplitude and shortening of latency seen with the age-related emergence of a more pruned, convergent topology. It is inferred that the normal connection topology of controls results in more focused excitation with repeated pure tones, whereas the poor decremental response in patients points to a lack of the normal topology. Finally, the latency of the novelty $\mathrm{Nc}$ is shortened. That is, during complex acoustic processing the connection architecture in WS failed to activate the P300 network, but instead induced premature activation 'downstream' in the $N c$ network. A role of epilepsy in these ERP changes appears likely. Longer treatment lag was associated with loss of the left novelty P300 amplitude relative to the right. The greater the duration of spasms (time from recognition to remission; a proxy for effective treatment) the longer was the left novelty P300 latency. If the ERP findings represent effects of infantile spasms on the connection topology of the acoustic processing network, treatment lag might accentuate this in the left hemisphere whose protracted maturational time-course confers it a particular vulnerability. ${ }^{\mathbf{4 2}}$ 


\section{LIMITATIONS}

The treatment lag in this study reflects continued challenges for primary care medical professionals in recognising WS. ${ }^{43}$ The use of retrospective parent-reported spasm onset is of indeterminate reliability, but is pragmatic in the absence of a superior alternative. Psychometrics could not be performed in all patients. Non-attendance was less than the United Kingdom norm for paediatrics of one-quarter. ${ }^{44}$ Testing could not be performed due to persistent agitation in one-quarter. Mood in infants can be constitutional but parental history of mood disorder was not specifically elicited. Parents considered the infant's mood to have changed from the pre-morbid temperament in all cases. Therefore, a consequence of IS or its treatment cannot be discounted. High dose VGB produces adverse effects on mood, including agitation and insomnia in $8.8 \%$ of children aged 2 months to 12 years. ${ }^{\mathbf{4 5}}$ The effect is greater with younger age. ${ }^{45}$

ERP studies are subject to a number of potential pitfalls. There is a concern about validity. If ERPs were 'concealed' within the background EEG in patients, then all components should have been affected. Moreover, the background EEG showed no visual or spectral group difference. [UNPUBLISHED FREQUENCY ANALYSIS DATA] A validation procedure (see Methods) provided results [Supplementary figures 13-16] that indicate that the measured ERPs are not artifacts. Emergence of between-group RS difference with auditory stimulation is consistent with re-organisation of background activity underlying ERPs. 
The lack of a direct correlation of ERPs to the BSID-II weakened the study's descriptive adequacy. The 'floor effect' in patients' BSID-II would have limited the statistical power for demonstrating this relationship. Treatment confound also existed. Serial measurement in IS has firmly established the benefit of treatment for promoting partial recovery of general cognitive function. ${ }^{46}$ Lack of longitudinal (pre- and posttreatment) psychometry precluded direct evaluation of whether treatment produced a deleterious effect on ERPs and cognitive function in this sample. There is no published data on the ERP effect of typical high Vigabatrin and steroid dose used for IS. VGB use was short-term (under a month at the time of ERP), but high cumulative VGB doses harbour a theoretical risk of altering cortical maturation. ${ }^{47}$ The lack of a dose relationship between VGB and the ERP findings would not support a linear VGB-induced effect, although a dose-thresholded effect cannot be excluded.

Finally, this study is unable to situate the nosology of uWS patients' poor language within the most accepted (Hickok-Poeppel, HP) model. ${ }^{5}$ The HP model concerns clinical language function whereas pre-linguistic auditory processing was tested here. The HP model is based on adults and postulates ventral pathways that are specialized for language comprehension; and dorsal pathways which support the expression of inner language. ${ }^{\mathbf{5}}$ There is evidence of poor ventral language system function in children with epilepsy. ${ }^{48}$ The formal assessment of ventral language processing using speech (phoneme)-related ERPs in a different group of WS patients (in preparation) is expected to help situate the language pathology in WS within the HP classification. 


\section{CONCLUSION AND FUTURE DIRECTIONS}

Complex sound processing showed abnormal lateralization on ERP, reminiscent of the pattern for language in early epilepsy. ${ }^{48}$ The findings of this study are consistent with alteration, rather than persisting immaturity, of the cortical network for acoustic processing. Pre-linguistic acoustic processing, a prerequisite for language acquisition, was impaired in the setting of regressed language one month into uWS. The persistence of an altered network for complex acoustic processing might contribute to the severe longterm difficulty with language following infantile spasms. Due to the key role of the temporal lobe in early cognition, ${ }^{49}$ the effect of epilepsy on temporal lobe function in children manifests in both language and cognition. ${ }^{\mathbf{5 0}}$ The impairments of acoustic processing and cognition (BSID-II: moderate to severe cognitive disability) demonstrated here in uWS patients are consistent with this notion. Follow up longitudinal data are required to relate ERP measures of complex acoustic stimulus processing to longterm language performance. The elucidation of this might permit more precise evaluation of nootropic treatments in uWS. 


\section{Key Points}

- Cortical acoustic processing of spectrally complex sound is defective at a month following successful treatment of IS. This is evidenced by reduced novelty P300 ERP amplitude in patients (half of control value).

- The connection topology of the auditory processing cortex in patients differs from controls, with the novelty P300 ERP lateralising abnormally.

- Epilepsy appears to play a role in the alteration of network function since longer treatment lag was associated with greater loss of the left novelty P300 amplitude. 
STATEMENT ON ETHICAL PUBLICATION: We confirm that we have read the Journal's position on issues involved in ethical publication and affirm that this report is consistent with those guidelines.

DISCLOSURES: None of the authors has any conflict of interest to disclose.

ACKNOWLEDGEMENT: We wish to thank the study participants and their parents. The physiologists at the clinical neurophysiology department Great Ormond Street Hospital are acknowledged for facilitating the ERP recordings. 


\section{Tables}

Table 1: The patient characteristics

Table 2: Event-Related Potentials

\section{$\underline{\text { Figure legends }}$}

\section{Figure I:}

Scalp topography of the MMN showing anterior and centrotemporal electrodes (patients - broken line; controls - bold line). The MMN was larger in patients than in controls (arrow at Fz).

\section{Figure II:}

Scalp topography of the novelty response (patients - broken line; controls - bold line). Patients showed diminished novelty P300 response at mid-temporal electrodes bilaterally (arrow at T3 and T4)

\section{Figure III:}

The mean N100 amplitude measured over the mid-temporal lobe electrodes (T3, T4) to iterations of the $1000 \mathrm{~Hz}$ standard tone in controls and patients. The upward slope on the graph of the control group is repetition suppression, which is not seen in the patient group (right figure). 


\section{Supplementary Tables}

Supplementary Table 1: The control characteristics

Supplementary Table 2: The Bayley scores for patients and controls

Supplementary Table 3: The frontocentral and mid-temporal Mismatch Negativity (MMN)

Supplementary Table 4: The frontocentral MMN

Supplementary Table 5: The mid-temporal MMN

Supplementary Table 6: The frontocentral and mid-temporal novelty P300

Supplementary Table 7: The frontocentral P300

Supplementary Table 8: The mid-temporal P300

\section{$\underline{\text { Supplementary figure legends }}$}

\section{Supplementary figure 1:}

The mismatch negativity amplitude over successive presentations of the deviant $(2000 \mathrm{~Hz})$ pure tone stimulus. The mid-temporal MMN amplitude (average of T3 and T4) for groups of 5 deviants shown in chronological order from left to right.

\section{Supplementary figure 2:}

The novelty P300 amplitude at the mid-temporal $(\mathrm{T} 3, \mathrm{~T} 4)$ and frontocentral $(\mathrm{Fz}, \mathrm{Cz})$ electrodes.

\section{Supplementary figure 3:}

The left-minus-right difference of the change in P300 amplitude at the mid-temporal electrodes over the first twenty presentations of novelty stimuli was anticorrelated with the treatment lag.

\section{Supplementary figure 4:}

The change in the P300 latency over the first twenty presentations of novelty stimuli differed with patients failing to show the normal shortening of the P300 latency at T3.

\section{Supplementary figure 5:}

The left-minus-right difference of the change in P300 latency at the mid-temporal electrodes over the first twenty presentations of novelty stimuli correlated with duration of infantile spasms.

\section{Supplementary figure 6:}

Group grand average novelty ERP. The earlier peak of the novelty $\mathrm{Nc}$ is indicated (arrows).

\section{Supplementary figures $7 \& 8$ :}

The novelty ERP in single control subjects. The arrow indicates the novelty P300.

\section{Supplementary figures $9 \& 10$ :}

The novelty ERP in single patient subjects.

\section{Supplementary figures $11 \& 12$ :}

Single-subject N100 ERP waveforms to the standard $(1000 \mathrm{~Hz})$ and deviant $(2000$ $\mathrm{Hz}$ ) tones for a control and a patient. The arrow indicates the enhanced response to the deviant (MMN) in the patient. 


\section{Supplementary figures 13-16:}

Group ERPs demonstrating lack of response when sound source decoupled, compared to when sound was presented. 


\section{$\underline{\text { Tables }}$}

Table 1: The patient characteristics

\begin{tabular}{|c|c|c|c|c|c|c|c|c|}
\hline PATIENT & SEX & $\begin{array}{l}\text { Age at } \\
\text { ERP } \\
\text { (mo.) }\end{array}$ & $\begin{array}{l}\text { Age } \\
\text { at spasm } \\
\text { onset } \\
\text { (mo.) }\end{array}$ & $\begin{array}{l}\text { Rx } \\
\mathrm{Lag} \\
\text { (wks) }\end{array}$ & $\begin{array}{l}\text { Age } \\
\text { at Rx } \\
\text { start (mo.) }\end{array}$ & $\begin{array}{l}\text { Age at } \\
\text { spasm } \\
\text { cessation } \\
\text { (mo.) }\end{array}$ & $\begin{array}{l}\text { Rx time } \\
\text { to spasm } \\
\text { cessation } \\
\text { (mo.) }\end{array}$ & $\mathrm{Rx}$ \\
\hline 1. & $\mathrm{~F}$ & 9 & 7 & 3 & 7 & 9 & 2 & $\begin{array}{l}\text { STER } \\
\text { VGB }\end{array}$ \\
\hline 2. & $\mathrm{~F}$ & 11 & 4 & 8 & 6 & 9 & 3 & $\begin{array}{l}\text { STER } \\
\text { VGB }\end{array}$ \\
\hline 3. & $\mathrm{M}$ & 11 & 6 & 4 & 7 & 9 & 2 & $\mathrm{VGB}^{\mathrm{b}}$ \\
\hline 4. & $\mathrm{M}$ & 6 & 5 & 4 & 6 & 6 & $<1$ & $\mathrm{VGB}^{\mathrm{b}}$ \\
\hline 5. & $\mathrm{~F}$ & 8 & 4 & 8 & 6 & 6 & $<1$ & $\mathrm{VGB}^{\mathrm{b}}$ \\
\hline 6. & $\mathrm{M}$ & 7 & 4 & 8 & 6 & 6 & $<1$ & $\mathrm{VGB}^{\mathrm{b}}$ \\
\hline 7. & $\mathrm{~F}$ & 7 & 6 & 4 & 7 & 7 & $<1$ & $\mathrm{VGB}^{\mathrm{b}}$ \\
\hline 8. & $\mathrm{M}$ & 10 & 6 & 4 & 7 & 8 & 1 & $\mathrm{VGB}^{\mathrm{b}}$ \\
\hline 9. & $\mathrm{M}$ & 7 & 5 & 3 & 5 & 6 & 1 & $\mathrm{VGB}^{b}$ \\
\hline 10. & $\mathrm{M}$ & 5 & 4 & 4 & 5 & 5 & $<1$ & $\operatorname{VGB}^{\mathrm{a}}$ \\
\hline 11. & $\mathrm{~F}$ & 9 & 5 & 4 & 6 & 6 & $<1$ & STER \\
\hline 12. & $\mathrm{~F}$ & 10 & 4 & 20 & 9 & 10 & 1 & $\begin{array}{l}\text { VGB }^{b} \\
\text { VPA }\end{array}$ \\
\hline 13. & $\mathrm{M}$ & 6 & 4 & 2 & 4 & 5 & 1 & $\mathrm{VGB}^{b}$ \\
\hline 14. & $\mathrm{M}$ & 8 & 5 & 4 & 6 & 6 & $<1$ & $\mathrm{VGB}^{b}$ \\
\hline 15. & $\mathrm{~F}$ & 10 & 7 & 4 & 8 & 8 & $<1$ & $\begin{array}{l}\text { VGB } \\
\text { VPA }\end{array}$ \\
\hline 16. & $\mathrm{M}$ & 7 & 6 & 2 & 6 & 6 & $<1$ & $\mathrm{VGB}^{b}$ \\
\hline 17. & $\mathrm{~F}$ & 7 & 5 & 2 & 6 & 6 & $<1$ & $\mathrm{VGB}^{\mathrm{b}}$ \\
\hline 18. & $\mathrm{~F}$ & 6 & 4 & 8 & 6 & 6 & $<1$ & $\operatorname{VGB}^{\mathrm{a}}$ \\
\hline 19. & $\mathrm{~F}$ & 8 & 7 & 2 & 7 & 7 & $<1$ & $\mathrm{VGB}^{b}$ \\
\hline 20. & $\mathrm{M}$ & 11 & 7 & 4 & 8 & 11 & 3 & $\begin{array}{l}\text { STER } \\
\text { VGB }\end{array}$ \\
\hline 21. & $\mathrm{~F}$ & 7 & 5 & 2 & 5 & 6 & $<1$ & $\mathrm{VGB}^{b}$ \\
\hline 22. & $\mathrm{~F}$ & 8 & 6 & 3 & 7 & 7 & $<1$ & STER \\
\hline
\end{tabular}

\footnotetext{
Abbreviations

Rx - treatment, VGB - Vigabatrin, STER - Prednisolone; VPA- Sodium valproate VGB doses: ${ }^{\text {a }}$ 50-99 mg/kg/day; ${ }^{\text {b }} 100-150 \mathrm{mg} / \mathrm{kg} /$ day
} 
Table 2: Event-Related Potentials

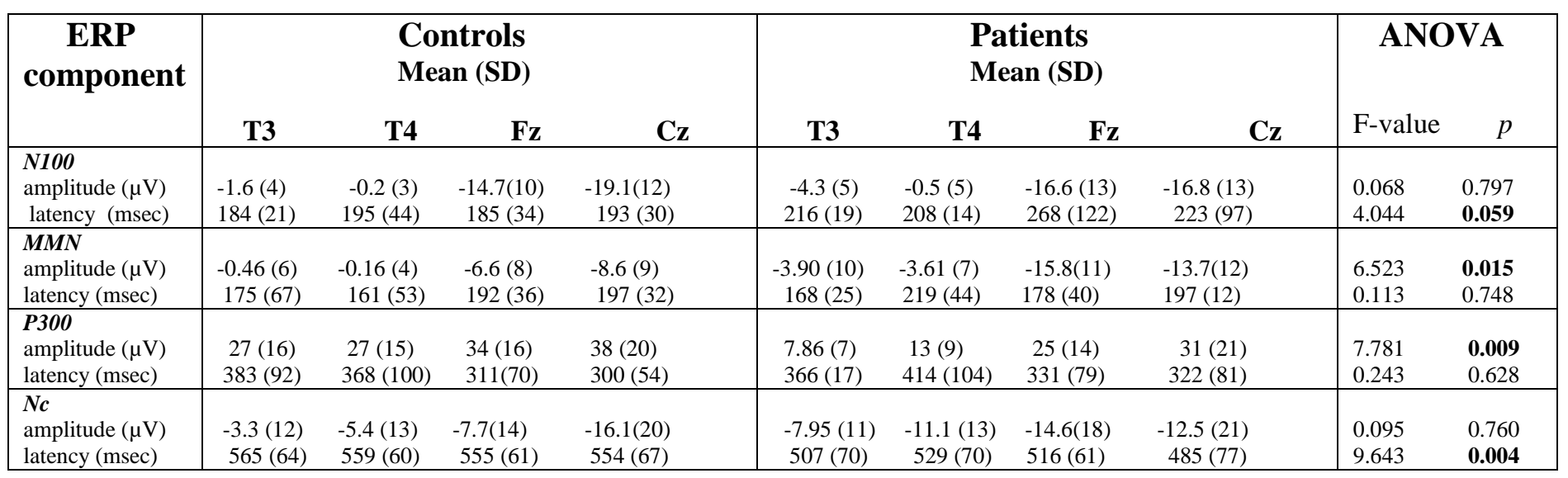


Figures

Figure I

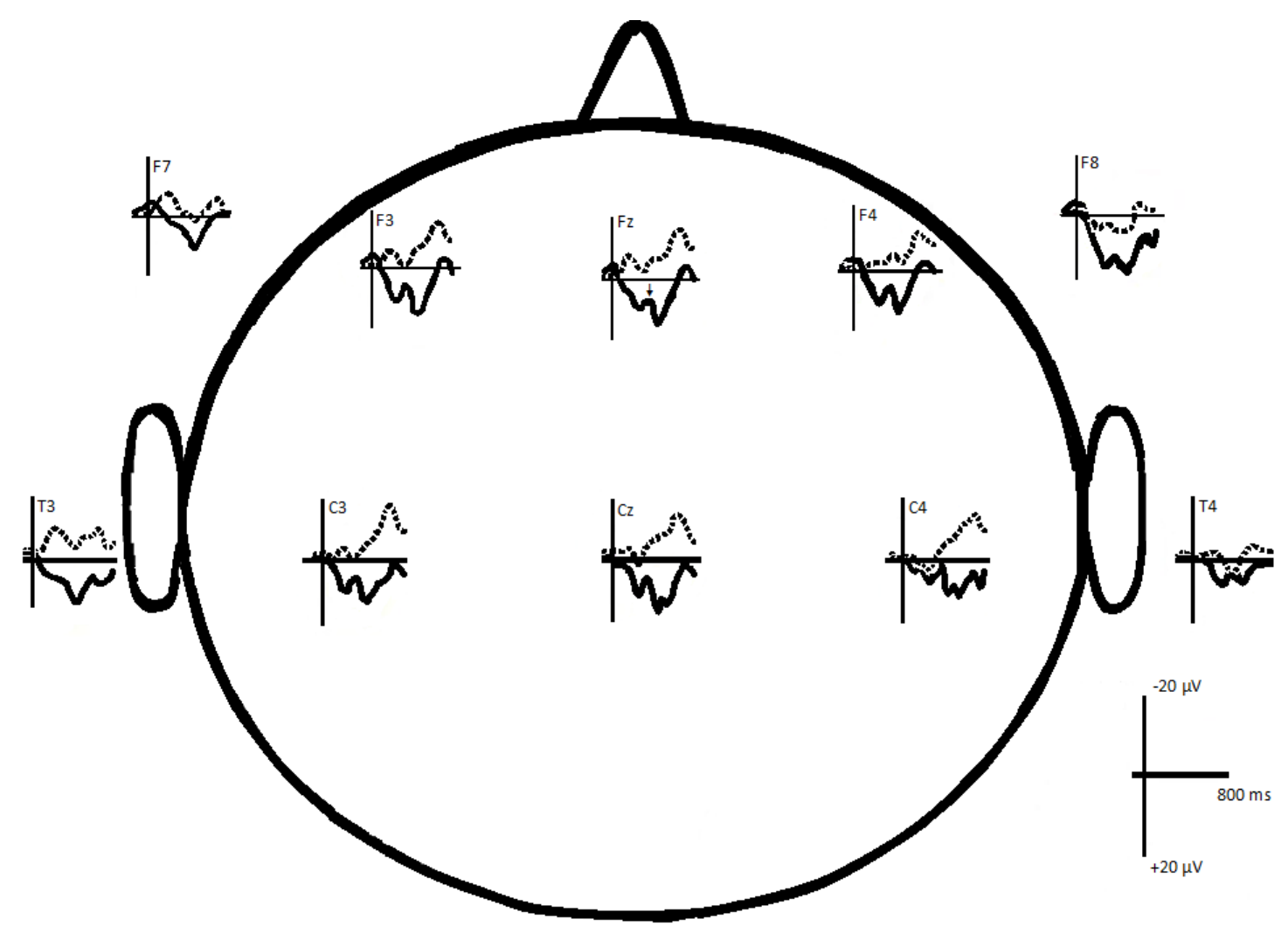


Figure II

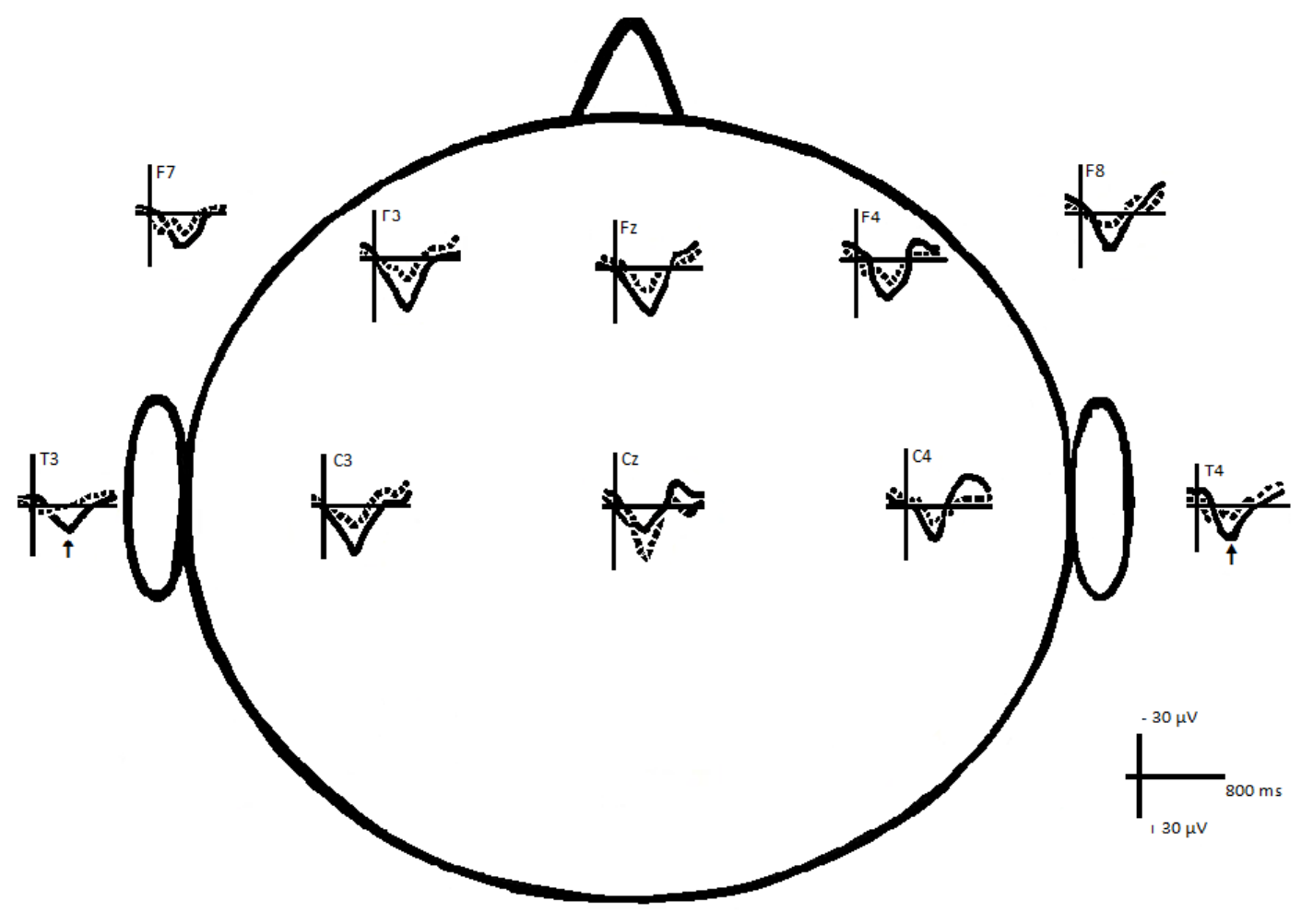


Figure III
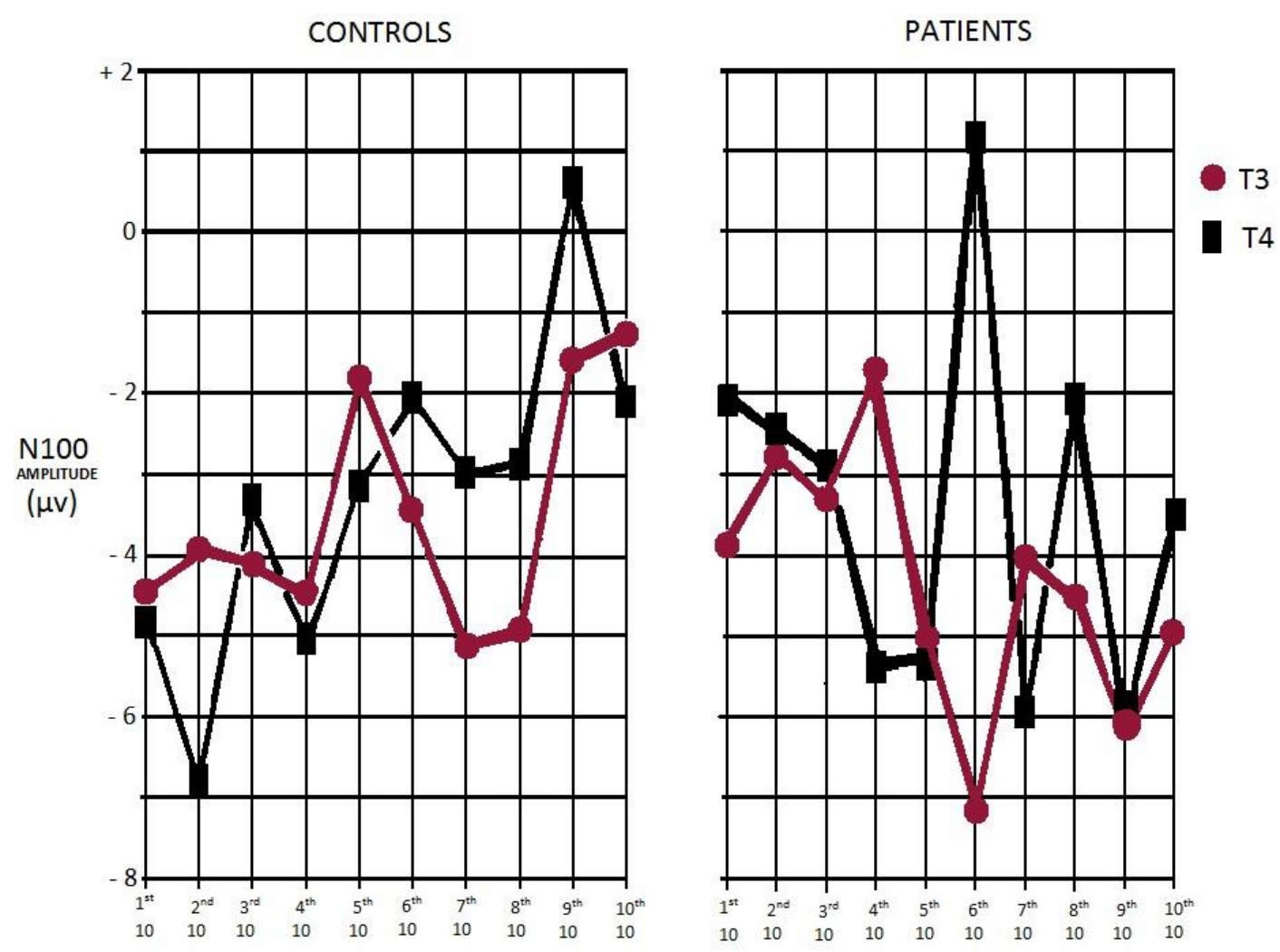


\section{References}

1. Neville B. Epileptic encephalopathy. Ann Indian Acad Neurol 2007;10:3-6.

2. Fosi $\mathrm{T}$, Chu $\mathrm{C}$, Chong WK, et al. Quantitative magnetic resonance imaging evidence for altered structural remodeling of the temporal lobe in West syndrome. Epilepsia $2015 ; 56: 608-16$.

3. Benn EK, Hesdorffer DC, Levy SR, et al. Parental report of behavioral and cognitive diagnoses in childhood-onset epilepsy: a case-sibling-controlled analysis. Epilepsy Behav 2010; 18: 276-279.

4. Monjauze $\mathrm{C}$, Broadbent $\mathrm{H}$, Boyd SG, et al. Language deficits and altered hemispheric lateralization in young people in remission from BECTS. Epilepsia 2011;52:e79-83.

5. Hickok G, Poeppel D. The cortical organization of speech processing Nat Rev Neurosci 2007;8:393-402.

6. Guzzetta F. Behavioral assessment of language brain processing in the first year of life. Eur J Paediatr Neurol 2014;18:551-7.

7. Korkman M, Granström ML, Appelqvist K, et al. Neuropsychological characteristics of five children with the Landau-Kleffner syndrome: dissociation of auditory and phonological discrimination. J Int Neuropsychol Soc 1998;4:566-75.

8. Boyd SG, Rivera-Gaxiola M, Towell AD, et al. Discrimination of speech sounds in a boy with Landau-Kleffner syndrome: an intraoperative event-related potential study. Neuropediatrics 1996;27:211-5.

9. Honbolygó F, Csépe V, Fekésházy A, et al. Converging evidences on language impairment in Landau-Kleffner Syndrome revealed by behavioral and brain activity measures: a case study. Clin Neurophysiol 2006;117:295-305.

10. Paquette $N$, Vannasing $P$, Lefrançois $M$, et al. Neurophysiological correlates of auditory and language development: a mismatch negativity study. Dev Neuropsychol 2013;38:386-401.

11. Bavin EL, Grayden DB, Scotti K, et al. Testing auditory processing skills and their associations with language in 4-5-year-olds. Lang Speech 2010;53:31-47.

12. Novick B, Lovrich D, Vaughan HG Jr. Event-related potentials associated with the discrimination of acoustic and semantic aspects of speech. Neuropsychologia 1985;23:87-101.

13. Matsuo A, Matsuzaka T, Tsuru A, et al. Epidemiological and clinical studies of West syndrome in Nagasaki Prefecture, Japan. Brain Dev 2001;23:575-9.

14. Neville BG, Spratt HC, Birtwistle J. Early onset epileptic auditory and visual agnosia with spontaneous recovery associated with Tourette's syndrome. J Neurol Neurosurg Psychiatry 2001;71:560-1.

15. Hyde M. The N1 response and its applications. Audiol Neurootol 1997;2:281-307

16. Wellmer J, Weber B, Urbach $\mathrm{H}$, et al. Cerebral lesions can impair fMRI-based language lateralization. Epilepsia 2009;50:2213-24.

17. Bayley N. Bayley scales of infant and toddler development ( $3^{\text {rd }}$ edition). Houston, TX: PsychCorp; 2006.

18. Lux AL, Edwards SW, Hancock E, et al. The United Kingdom Infantile Spasms Study (UKISS) comparing hormone treatment with Vigabatrin on developmental and epilepsy outcomes to age 14 months: a multicentre randomised trial. Lancet Neurol 2005;4:712-7.

19. Werner KG, Fosi T, Boyd SG, et al. Temporal lobe impairment in West syndrome: event-related potential evidence. Ann Neurol 2015;77:47-57.

20. Wessinger CM, VanMeter J, Tian B, et al. Hierarchical organization of the human auditory cortex revealed by functional magnetic resonance imaging. J Cogn Neurosci 2001;13:1-7. 
21. Kuśmierek P, Malinowska M, Kowalska DM. Different effects of lesions to auditory core and belt cortex on auditory recognition in dogs. Exp Brain Res 2007;180:491508.

22. Pandya DN. Anatomy of the auditory cortex. Rev Neurol (Paris) 1995;151:486-94.

23. Plakke B, Romanski LM. Auditory connections and functions of prefrontal cortex. Front Neurosci 2014;8:199.

24. Liasis A, Towell A, Boyd S. Intracranial auditory detection and discrimination potentials as substrates of echoic memory in children. Brain Res Cogn Brain Res 1999;7:503-6.

25. Schönwiesner M, Rübsamen R, von Cramon DY. asymmetry for spectral and temporal processing in the human antero-lateral auditory belt cortex. Eur J Neurosci 2005;22:1521-8.

26. Miyajima M, Ohta K, Hara K, et al. Abnormal mismatch negativity for pure-tone sounds in temporal lobe epilepsy. Epilepsy Res 2011;94:149-57.

27. Rinne T, Alho K, Ilmoniemi RJ, et al. Separate time behaviors of the temporal and frontal mismatch negativity sources. Neuroimage 2000;12:14-9.

28. Shalgi S, Deouell LY. Direct evidence for differential roles of temporal and frontal components of auditory change detection. Neuropsychologia 2007;45(8):1878-88.

29. Gomot M, Giard MH, Roux S, et al. Maturation of frontal and temporal components of mismatch negativity (MMN) in children. Neuroreport 2000;11:3109-12.

30. Cooper RJ, Todd J, McGill K, et al. Auditory sensory memory and the aging brain: A mismatch negativity study. Neurobiol Aging 2006;27:752-62.

31. Knight RT, Scabini D, Woods DL, et al. Contributions of temporal-parietal junction to the human auditory P3. Brain Res 1989;502:109-16.

32. Alho K, Winkler I, Escera C, et al. Processing of novel sounds and frequency changes in the human auditory cortex: magnetoencephalographic recordings. Psychophysiology 1998;35:211-24.

33. Colombo M, Rodman HR, Gross CG. The effects of superior temporal cortex lesions on the processing and retention of auditory information in monkeys (Cebus apella). $\mathrm{J}$ Neurosci 1996;16:4501-17.

34. Werner K. Auditory processing in the syndrome of infantile spasms. PhD Thesis (2007). University College London

35. Moore JK. Maturation of human auditory cortex: implications for speech perception. Ann Otol Rhinol Laryngol Suppl 2002; 189:7-10.

36. Huttenlocher PR, Dabholkar AS. Regional differences in synaptogenesis in human cerebral cortex. J Comp Neurol 1997;387:167-78.

37. Adrian ED, Matthews BH. The interpretation of potential waves in the cortex. J Physiol 1934;81:440-71.

38. Adrian ED, Moruzzi G. Impulses in the pyramidal tract. J Physiol 1939;97(2):153-99

39. Kushnerenko E, Winkler I, Horváth J, et al. Processing acoustic change and novelty in newborn infants. Eur J Neurosci 2007;26:265-74.

40. Morr ML, Shafer VL, Kreuzer JA, et al. Maturation of mismatch negativity in typically developing infants and preschool children. Ear Hear 2002;23:118-36.

41. Briley PM, Krumbholz K. The specificity of stimulus-specific adaptation in human auditory cortex increases with repeated exposure to the adapting stimulus $\mathrm{J}$ Neurophysiol 2013;110:2679-88.

42. Raja Beharelle A, Dick AS, Josse G, et al. Left hemisphere regions are critical for language in the face of early left focal brain injury. Brain 2010;133:1707-1716.

43. Napuri S, LE Gall E, Dulac O, et al. Factors associated with treatment lag in infantile spasms. Dev Med Child Neurol 2010;52:1164-6.

44. Morris L, Haywood S. Why do patient miss appointments? A retrospective population study in paediatric outpatients in a metropolitan hospital. Arch Dis Child 2014;99: A96.

45. Elterman RD, Shields WD, Bittman RM, et al. Vigabatrin for the treatment of infantile spasms: final report of a randomized trial. J Child Neurol 2010; 25:1340-7. 
46. Humphrey A, MacLean C, Ploubidis GB, et al. Tuberous Sclerosis 2000 Study Group. Intellectual development before and after the onset of infantile spasms: a controlled prospective longitudinal study in tuberous sclerosis. Epilepsia 2014;55:108-16.

47. Juhász C, Muzik O, Chugani DC, et al. Prolonged vigabatrin treatment modifies developmental changes of GABA(A)-receptor binding in young children with epilepsy. Epilepsia 2001;42:1320-6.

48. Croft LJ, Baldeweg T, Sepeta L, et al. Vulnerability of the ventral language network in children with focal epilepsy. Brain 2014;137:2245-57.

49. Kaufman J, Csibra G, Johnson MH. Representing occluded objects in the human infant brain. Proc Biol Sci 2003;270(Suppl 2):s140-3.

50. Wilson SJ, Micallef S, Henderson A, et al. Developmental outcomes of childhoodonset temporal lobe epilepsy: a community-based study. Epilepsia 2012;53:1587-96. 


\section{SUPPLEMENTARY MATERIAL}




\section{SUPPLEMENTARY TABLES}

Supplementary Table 1: The control characteristics

\begin{tabular}{|l|l|l|}
\hline CONTROL & SEX & $\begin{array}{l}\text { AGE } \\
\text { (Mo. })\end{array}$ \\
\hline 1 & M & 10 \\
\hline 2 & F & 8 \\
\hline 3 & F & 3 \\
\hline 4 & M & 10 \\
\hline 5 & M & 12 \\
\hline 6 & M & 12 \\
\hline 7 & M & 10 \\
\hline 8 & F & 3 \\
\hline 9 & F & 3 \\
\hline 10 & M & 6 \\
\hline 11 & M & 5 \\
\hline 12 & M & 8 \\
\hline 13 & F & 6 \\
\hline 14 & F & 5 \\
\hline 15 & F & 9 \\
\hline 16 & M & 4 \\
\hline 17 & F & 4 \\
\hline 18 & F & 4 \\
\hline 19 & F & 8 \\
\hline 20 & M & 4 \\
\hline 21 & M & 12 \\
\hline 22 & F & 6 \\
\hline & & \\
\hline
\end{tabular}


Supplementary Table 2: The Bayley scores* for patients and control subjects

\begin{tabular}{|c|c|c|c|}
\hline SUBJECT & COGNITIVE & LANGUAGE & MOTOR \\
\hline Patient 1 & $55(0.01)$ & $68(0.02)$ & $47(<0.01)$ \\
\hline Patient 2 & $55(0.01)$ & $47(<0.01)$ & $46(<0.01)$ \\
\hline Patient 3 & $55(0.01)$ & $47(<0.01)$ & $46(<0.01)$ \\
\hline Patient 4 & $85(0.16)$ & $86(0.18)$ & $94(0.34)$ \\
\hline Patient 5 & $55(0.01)$ & $68(0.02)$ & $49(<0.01)$ \\
\hline Patient 6 & $\mathrm{n} / \mathrm{d}$ & $\mathrm{n} / \mathrm{d}$ & $\mathrm{n} / \mathrm{d}$ \\
\hline Patient 7 & $\mathrm{n} / \mathrm{d}$ & $\mathrm{n} / \mathrm{d}$ & $\mathrm{n} / \mathrm{d}$ \\
\hline Patient 8 & $\mathrm{n} / \mathrm{d}$ & $\mathrm{n} / \mathrm{d}$ & $\mathrm{n} / \mathrm{d}$ \\
\hline Patient 9 & $\mathrm{n} / \mathrm{d}$ & $\mathrm{n} / \mathrm{d}$ & $\mathrm{n} / \mathrm{d}$ \\
\hline Patient 10 & $\mathrm{n} / \mathrm{d}$ & $\mathrm{n} / \mathrm{d}$ & $\mathrm{n} / \mathrm{d}$ \\
\hline Patient 11 & $90(0.25)$ & $74(0.04)$ & $94(0.34)$ \\
\hline Patient 12 & $55(0.01)$ & $47(<0.01)$ & $46(<0.01)$ \\
\hline Patient 13 & $90(0.25)$ & $94(0.34)$ & $88(0.21)$ \\
\hline Patient 14 & $90(0.25)$ & $77(0.06)$ & $67(0.01)$ \\
\hline Patient 15 & $\mathrm{n} / \mathrm{d}$ & $\mathrm{n} / \mathrm{d}$ & $\mathrm{n} / \mathrm{d}$ \\
\hline Patient 16 & $55(0.01)$ & $47(<0.01)$ & $46(<0.01)$ \\
\hline Patient 17 & $\mathrm{n} / \mathrm{d}$ & $\mathrm{n} / \mathrm{d}$ & $\mathrm{n} / \mathrm{d}$ \\
\hline Patient 18 & $55(0.01)$ & $56(0.02)$ & $46(<0.01)$ \\
\hline Patient 19 & $55(0.01)$ & $47(<0.01)$ & $46(<0.01)$ \\
\hline Patient 20 & $55(0.01)$ & $47(<0.01)$ & $46(<0.01)$ \\
\hline Patient 21 & $\mathrm{n} / \mathrm{d}$ & $\mathrm{n} / \mathrm{d}$ & $\mathrm{n} / \mathrm{d}$ \\
\hline Patient 22 & $\mathrm{n} / \mathrm{d}$ & $\mathrm{n} / \mathrm{d}$ & $\mathrm{n} / \mathrm{d}$ \\
\hline Control 1 & $115(0.84)$ & $89(0.27)$ & $94(0.34)$ \\
\hline Control 2 & $65(0.01)$ & $47(<0.01)$ & $46(<0.01)$ \\
\hline Control 3 & $110(0.75)$ & $91(0.27)$ & $88(0.21)$ \\
\hline Control 4 & $95(0.37)$ & $91(0.27)$ & $85(0.16)$ \\
\hline Control 5 & $105(0.63)$ & $86(0.18)$ & $85(0.16)$ \\
\hline
\end{tabular}




\begin{tabular}{|c|c|c|c|}
\hline Control 6 & $\mathrm{n} / \mathrm{d}$ & $\mathrm{n} / \mathrm{d}$ & $\mathrm{n} / \mathrm{d}$ \\
\hline Control 7 & $100(0.50)$ & $97(0.42)$ & $103(0.58)$ \\
\hline Control 8 & $120(0.91)$ & $115(0.84)$ & $115(0.84)$ \\
\hline Control 9 & $55(0.1)$ & $86(0.18)$ & $79(0.08)$ \\
\hline Control 10 & $\mathrm{n} / \mathrm{d}$ & $\mathrm{n} / \mathrm{d}$ & $\mathrm{n} / \mathrm{d}$ \\
\hline Control 11 & $\mathrm{n} / \mathrm{d}$ & $\mathrm{n} / \mathrm{d}$ & $\mathrm{n} / \mathrm{d}$ \\
\hline Control 12 & $\mathrm{n} / \mathrm{d}$ & $\mathrm{n} / \mathrm{d}$ & $\mathrm{n} / \mathrm{d}$ \\
\hline Control 13 & $\mathrm{n} / \mathrm{d}$ & $\mathrm{n} / \mathrm{d}$ & $\mathrm{n} / \mathrm{d}$ \\
\hline Control 14 & $\mathrm{n} / \mathrm{d}$ & $\mathrm{n} / \mathrm{d}$ & $\mathrm{n} / \mathrm{d}$ \\
\hline Control 15 & $100(0.50)$ & $97(0.42)$ & $97(0.42)$ \\
\hline Control 16 & $\mathrm{n} / \mathrm{d}$ & $\mathrm{n} / \mathrm{d}$ & $\mathrm{n} / \mathrm{d}$ \\
\hline Control 17 & $\mathrm{n} / \mathrm{d}$ & $\mathrm{n} / \mathrm{d}$ & $\mathrm{n} / \mathrm{d}$ \\
\hline Control 18 & $\mathrm{n} / \mathrm{d}$ & $\mathrm{n} / \mathrm{d}$ & $\mathrm{n} / \mathrm{d}$ \\
\hline Control 19 & $110(0.75)$ & $100(0.50)$ & $112(0.79)$ \\
\hline Control 20 & $\mathrm{n} / \mathrm{d}$ & $\mathrm{n} / \mathrm{d}$ & $\mathrm{n} / \mathrm{d}$ \\
\hline Control 21 & $95(0.37)$ & $86(0.18)$ & $94(0.34)$ \\
\hline Control 22 & $\mathrm{n} / \mathrm{d}$ & $\mathrm{n} / \mathrm{d}$ & $\mathrm{n} / \mathrm{d}$ \\
\hline
\end{tabular}

Legend: The composite Bayley score (normalised score for age) is shown for cognition, language and motor function. The subject centile rank is in brackets, for example 0.75 is the $75^{\text {th }}$ centile. 
Supplementary Table 3: The frontocentral and mid-temporal Mismatch Negativity (MMN

\begin{tabular}{|c|c|c|c|c|c|c|c|c|c|c|}
\hline \multirow[t]{2}{*}{$\begin{array}{c}\text { ERP } \\
\text { component }\end{array}$} & \multicolumn{4}{|c|}{$\begin{array}{l}\text { Controls } \\
\text { Mean (SD) }\end{array}$} & \multicolumn{4}{|c|}{$\begin{array}{l}\text { Patients } \\
\text { Mean (SD) }\end{array}$} & \multicolumn{2}{|c|}{ ANOVA } \\
\hline & T3 & T4 & $\mathbf{F z}$ & $\mathbf{C z}$ & T3 & T4 & $\mathbf{F z}$ & $\mathrm{Cz}$ & F-value & $p$ \\
\hline
\end{tabular}


Supplementary Table 4: The frontocentral MMN

\begin{tabular}{|c|c|c|c|c|c|c|}
\hline \multirow[t]{2}{*}{$\begin{array}{c}\text { ERP } \\
\text { component }\end{array}$} & \multicolumn{2}{|c|}{$\begin{array}{l}\text { Controls } \\
\text { Mean (SD) }\end{array}$} & \multicolumn{2}{|c|}{$\begin{array}{l}\text { Patients } \\
\text { Mean (SD) }\end{array}$} & \multicolumn{2}{|c|}{ ANOVA } \\
\hline & $\mathbf{F z}$ & $\mathrm{Cz}$ & $\mathbf{F z}$ & $\mathrm{Cz}$ & F-value & $p$ \\
\hline $\begin{array}{l}M M N \\
\text { amplitude }(\mu \mathrm{V}) \\
\text { latency (msec) }\end{array}$ & $\begin{array}{l}-6.6(8) \\
192(36)\end{array}$ & $\begin{array}{l}-8.6(9) \\
197(32)\end{array}$ & $\begin{array}{l}-15.8(11) \\
178(40)\end{array}$ & $\begin{array}{c}-13.7(12) \\
197(12)\end{array}$ & $\begin{array}{l}\mathbf{6 . 7 9 8} \\
0.0001\end{array}$ & $\begin{array}{l}.013 \\
.994\end{array}$ \\
\hline
\end{tabular}


Supplementary Table 5: The mid-temporal MMN

\begin{tabular}{|c|c|c|c|c|c|c|}
\hline \multirow[t]{2}{*}{$\begin{array}{c}\text { ERP } \\
\text { component }\end{array}$} & \multicolumn{2}{|c|}{$\begin{array}{l}\text { Controls } \\
\text { Mean (SD) }\end{array}$} & \multicolumn{2}{|c|}{$\begin{array}{l}\text { Patients } \\
\text { Mean (SD) }\end{array}$} & \multicolumn{2}{|c|}{ ANOVA } \\
\hline & T3 & T4 & T3 & T4 & F-value & $p$ \\
\hline $\begin{array}{l}\boldsymbol{M M N} \\
\text { amplitude }(\mu \mathrm{V}) \\
\text { latency }(\mathrm{msec})\end{array}$ & $\begin{array}{c}-0.46(6) \\
134(42)\end{array}$ & $\begin{array}{c}-0.16(4) \\
136(53)\end{array}$ & $\begin{array}{c}-3.90(10) \\
166(60)\end{array}$ & $\begin{array}{c}-3.61(7) \\
195(49)\end{array}$ & $\begin{array}{r}5.38 \\
18.33\end{array}$ & $\begin{array}{r}0.026 \\
0.0001\end{array}$ \\
\hline
\end{tabular}


Supplementary Table 6: The frontocentral and mid-temporal novelty P300

\begin{tabular}{|c|c|c|c|c|c|c|c|c|c|c|}
\hline \multirow[t]{2}{*}{$\begin{array}{c}\text { ERP } \\
\text { component }\end{array}$} & \multicolumn{4}{|c|}{$\begin{array}{l}\text { Controls } \\
\text { Mean (SD) }\end{array}$} & \multicolumn{4}{|c|}{$\begin{array}{l}\text { Patients } \\
\text { Mean (SD) }\end{array}$} & \multicolumn{2}{|c|}{ ANOVA } \\
\hline & T3 & T4 & $\mathbf{F z}$ & $\mathbf{C z}$ & T3 & T4 & $\mathbf{F z}$ & $\mathbf{C z}$ & F-value & $p$ \\
\hline
\end{tabular}


Supplementary Table 7: The frontocentral P300

\begin{tabular}{|c|c|c|c|c|c|}
\hline \multirow{2}{*}{$\begin{array}{c}\text { ERP } \\
\text { component }\end{array}$} & $\begin{array}{r}\text { Controls } \\
\text { Mean (SD) }\end{array}$ & \multicolumn{2}{|c|}{$\begin{array}{l}\text { Patients } \\
\text { Mean (SD) }\end{array}$} & \multicolumn{2}{|c|}{ ANOVA } \\
\hline & $\mathbf{F z} \quad \mathbf{C z}$ & $\mathbf{F z}$ & $\mathbf{C z}$ & F-value & $p$ \\
\hline $\begin{array}{l}\text { P300 } \\
\text { Amplitude }(\mu \mathrm{V}) \\
\text { Latency }(\mathrm{msec})\end{array}$ & $\begin{array}{lc}34(16) & 38(20) \\
311(70) & 300(54)\end{array}$ & $\begin{array}{l}25(14) \\
331(79)\end{array}$ & $\begin{array}{r}31(21) \\
322(81)\end{array}$ & $\begin{array}{l}1.645 \\
0.884\end{array}$ & $\begin{array}{r}0.209 \\
0.354\end{array}$ \\
\hline
\end{tabular}


Supplementary Table 8: The mid-temporal P300

\begin{tabular}{|c|c|c|c|c|c|c|}
\hline \multirow{2}{*}{$\begin{array}{c}\text { ERP } \\
\text { component }\end{array}$} & \multicolumn{2}{|c|}{$\begin{array}{r}\text { Controls } \\
\text { Mean (SD) }\end{array}$} & \multicolumn{2}{|c|}{$\begin{array}{l}\text { Patients } \\
\text { Mean (SD) }\end{array}$} & \multicolumn{2}{|c|}{ ANOVA } \\
\hline & $\mathbf{T 3}$ & T4 & T3 & $\mathbf{T 4}$ & F-value & $p$ \\
\hline $\begin{array}{l}\text { P300 } \\
\text { Amplitude }(\mu \mathrm{V}) \\
\text { Latency }(\mathrm{msec})\end{array}$ & $\begin{array}{l}27(16) \\
383(92) \\
\end{array}$ & $\begin{array}{l}27(15) \\
368(100)\end{array}$ & $\begin{array}{l}7.86(7) \\
366(17)\end{array}$ & $\begin{array}{c}13(9) \\
414(104) \\
\end{array}$ & $\begin{array}{l}12.906 \\
0.008 \\
\end{array}$ & $\begin{array}{l}\mathbf{0 . 0 0 1} \\
0.930\end{array}$ \\
\hline
\end{tabular}




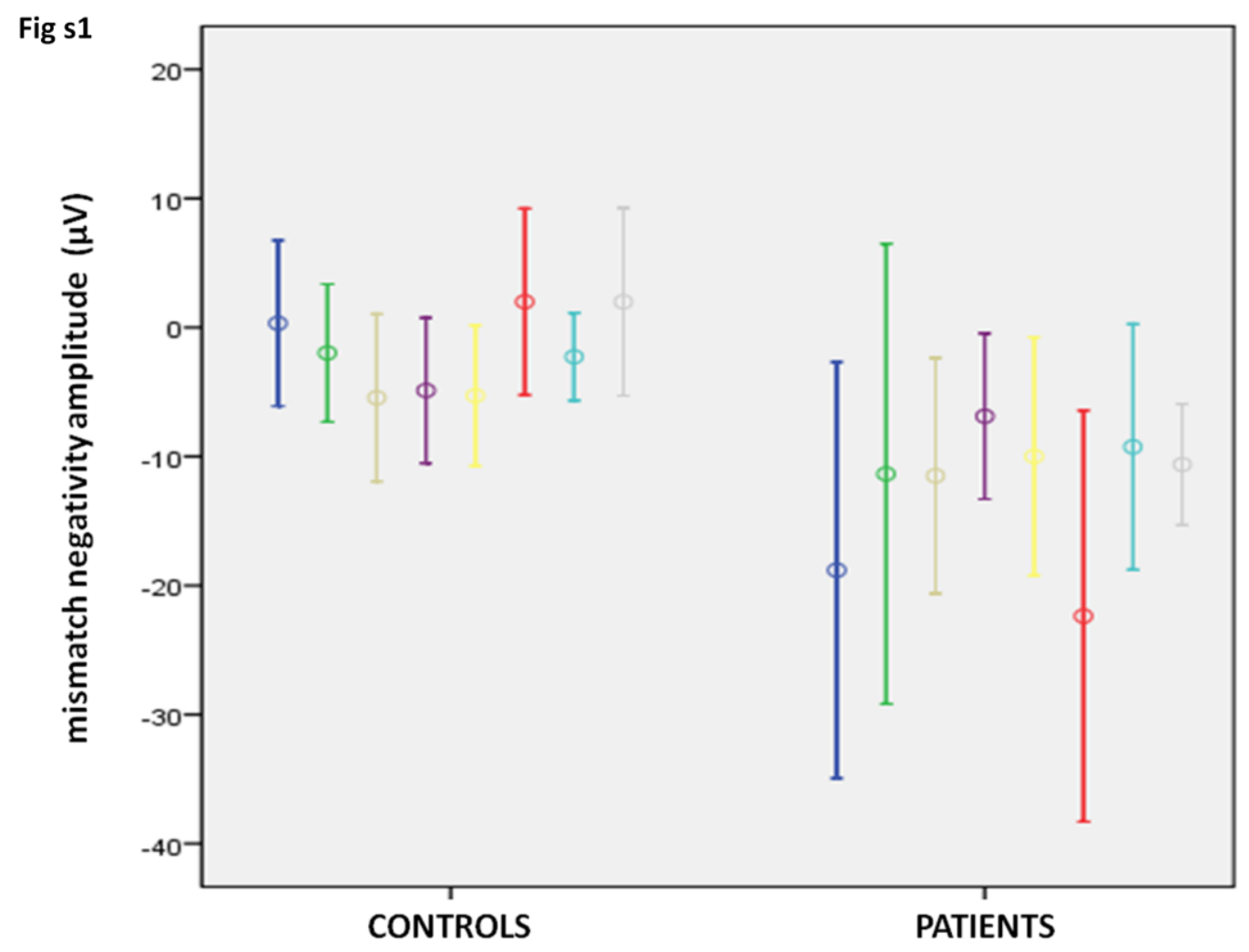




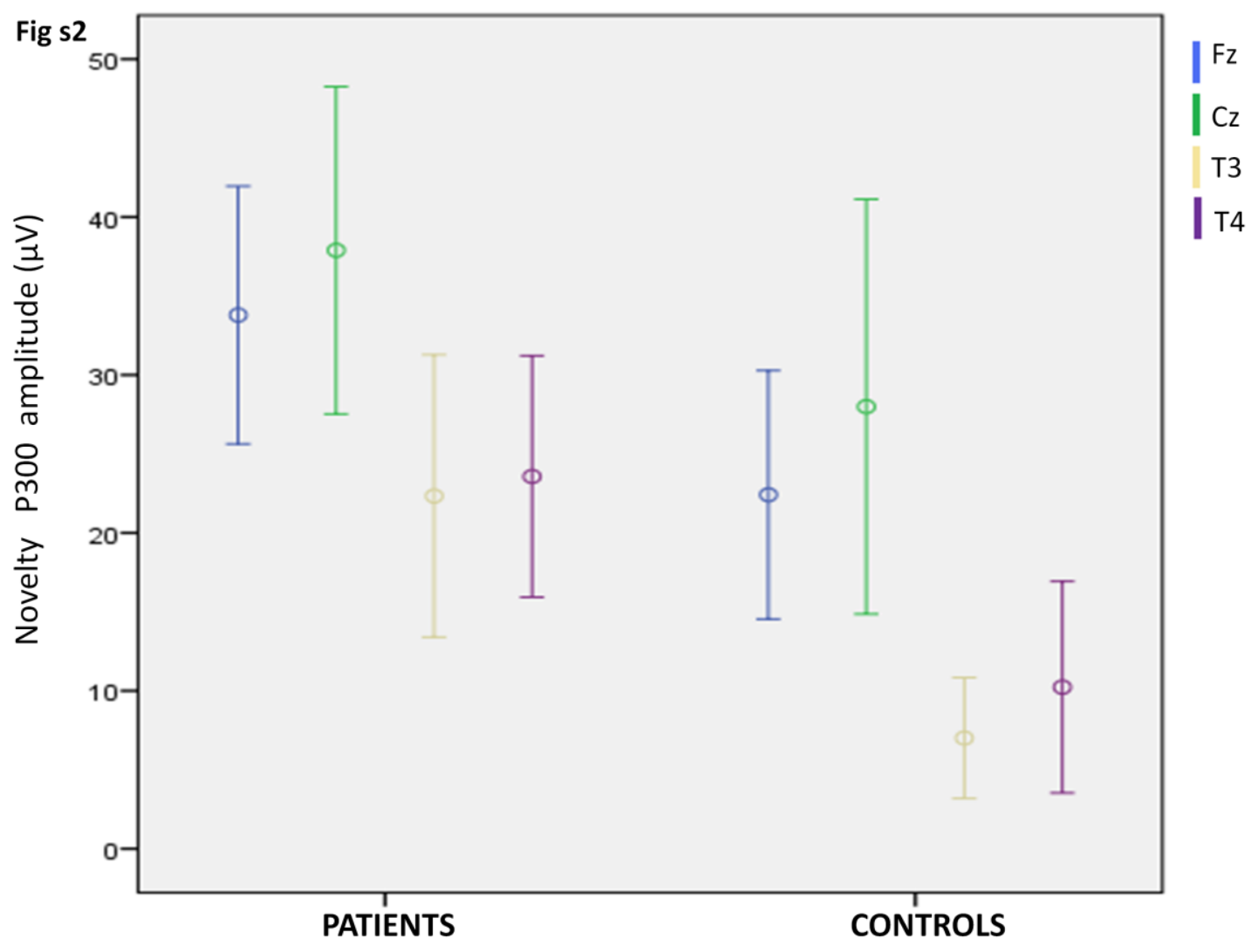




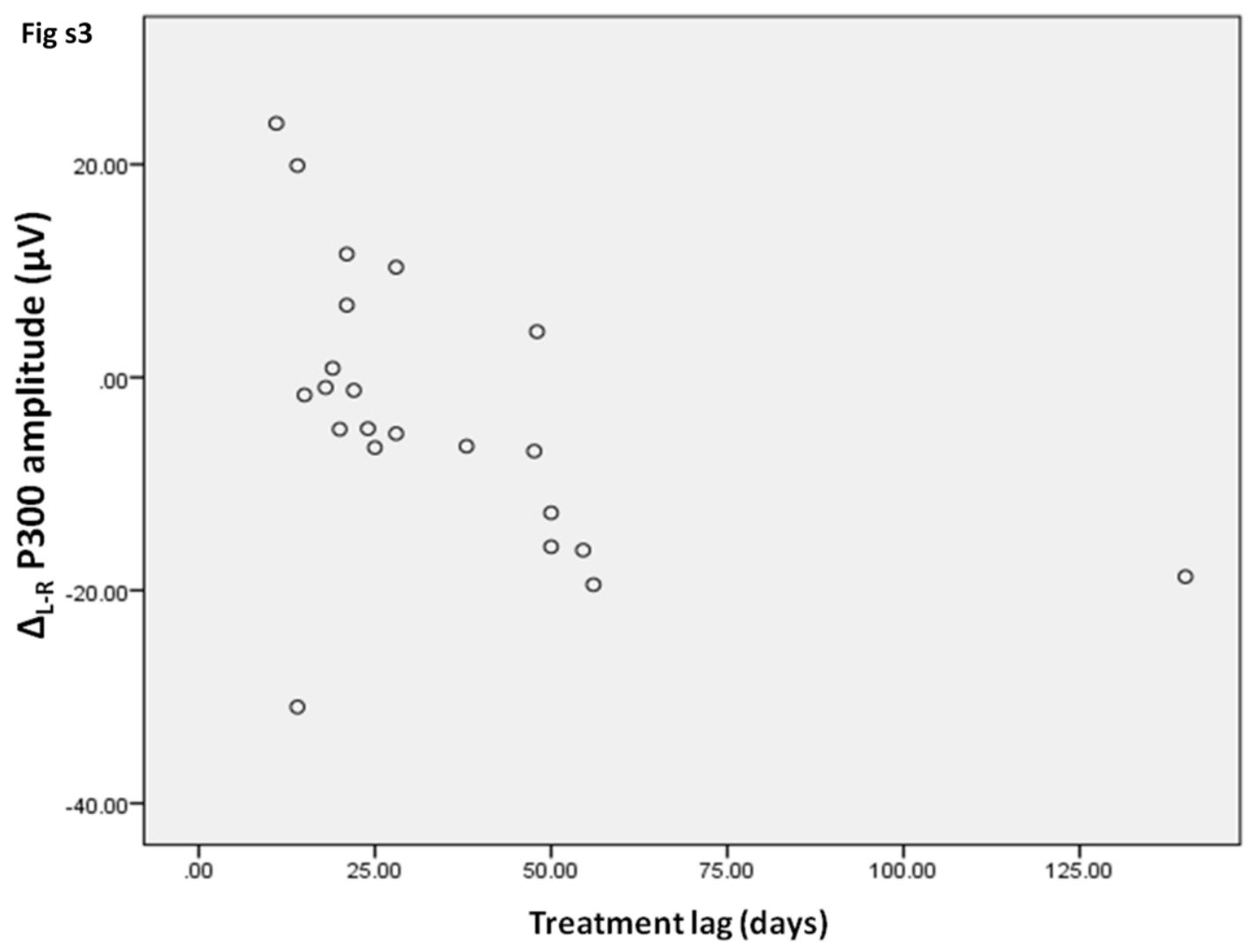




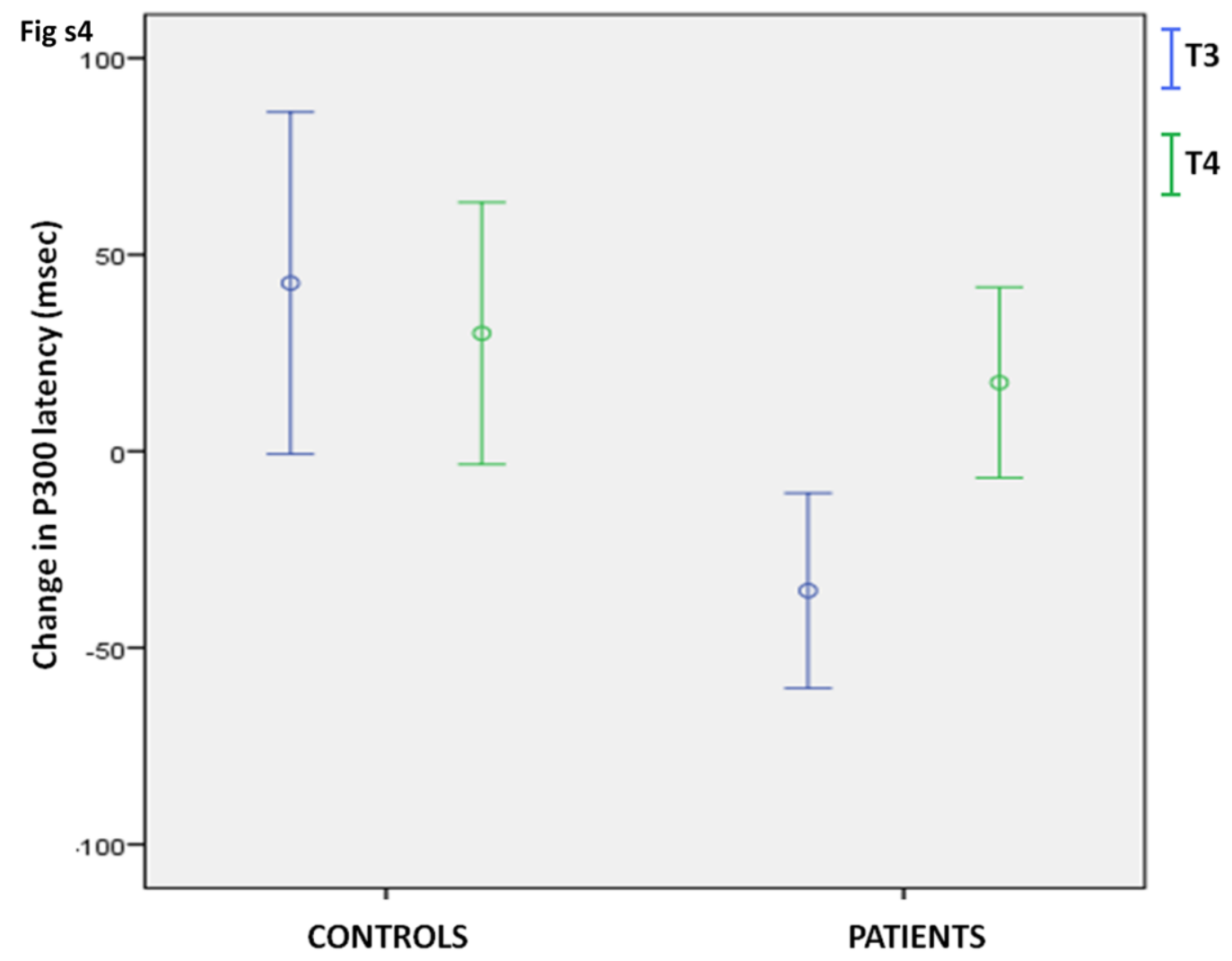




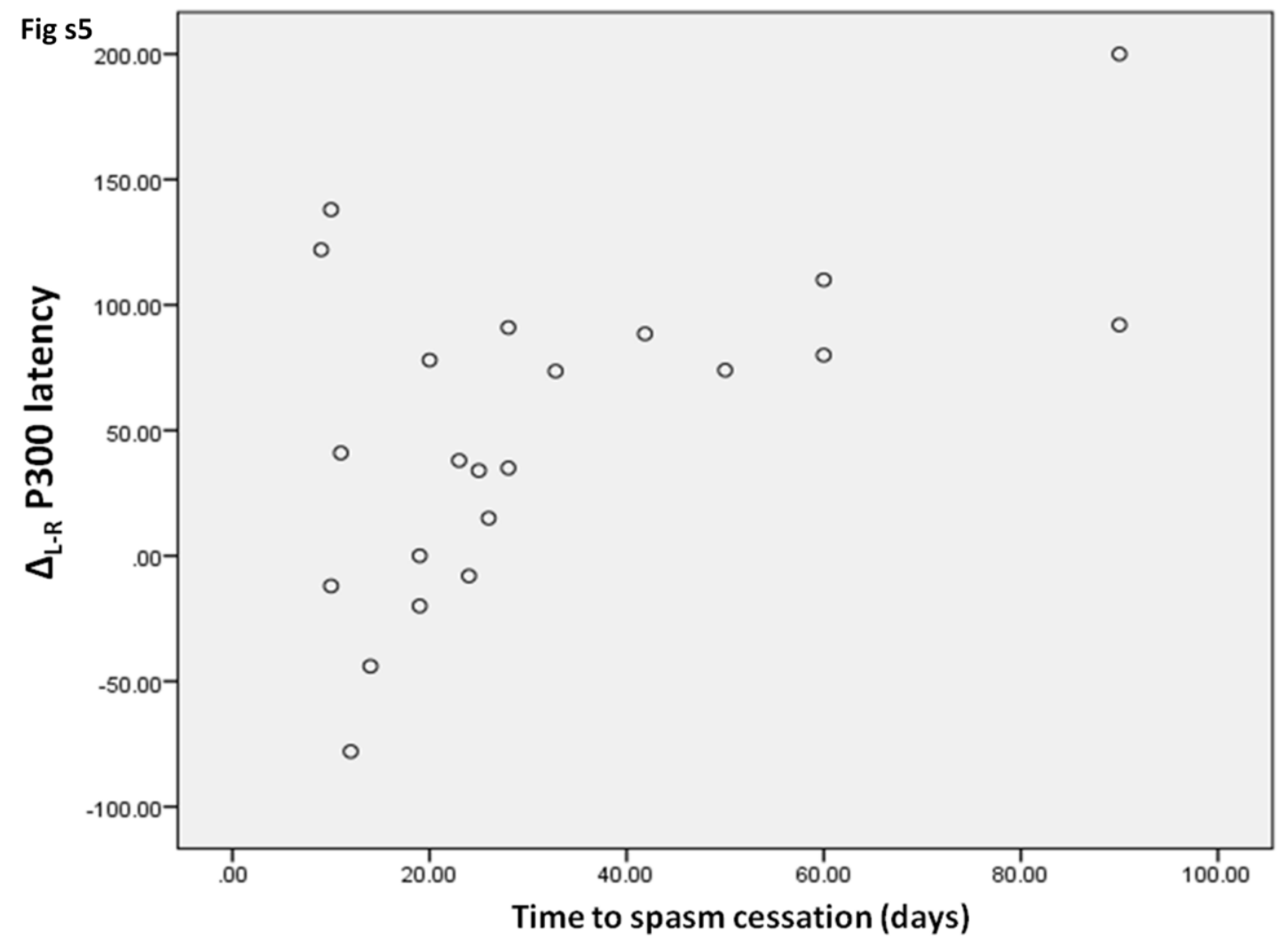


Fig s6

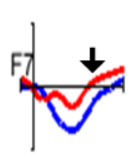

$\sqrt{4}$

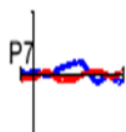

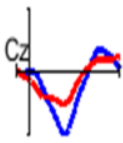

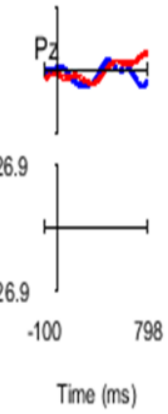

NOVELTY ERP GROUP COMPARISON

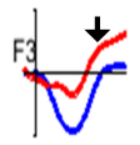

to<smiles>CC1(C)CCCC1(C)C</smiles>
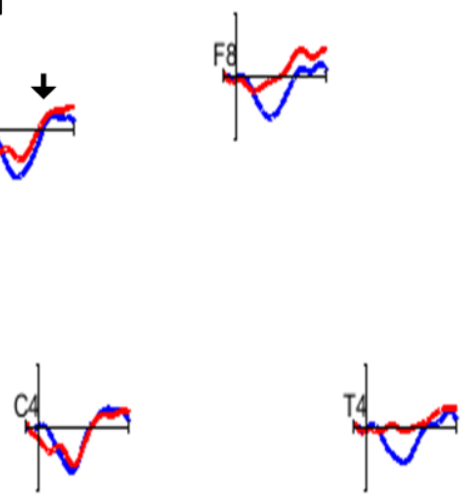
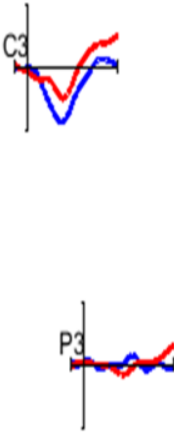
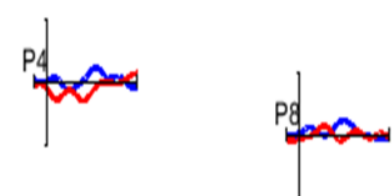

controls patients 
Fig s7

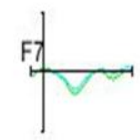

13

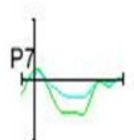

NOVELTY ERP SINGLE SUBJECT (CONTROL)
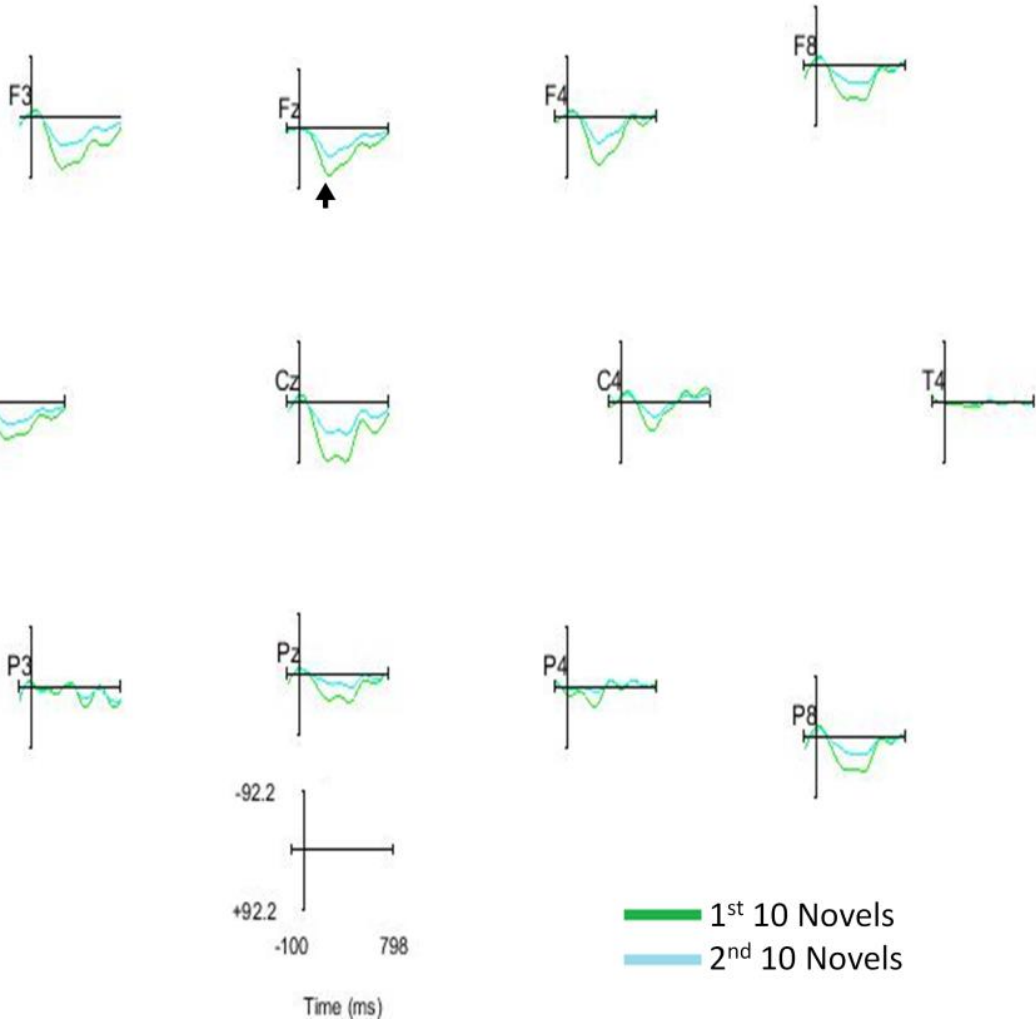

$1^{\text {st }} 10$ Novels

$2^{\text {nd }} 10$ Novels 
Fig s8
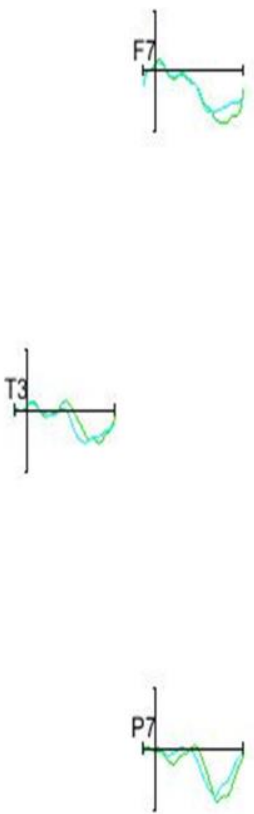

NOVELTY ERP SINGLE SUBJECT (CONTROL)
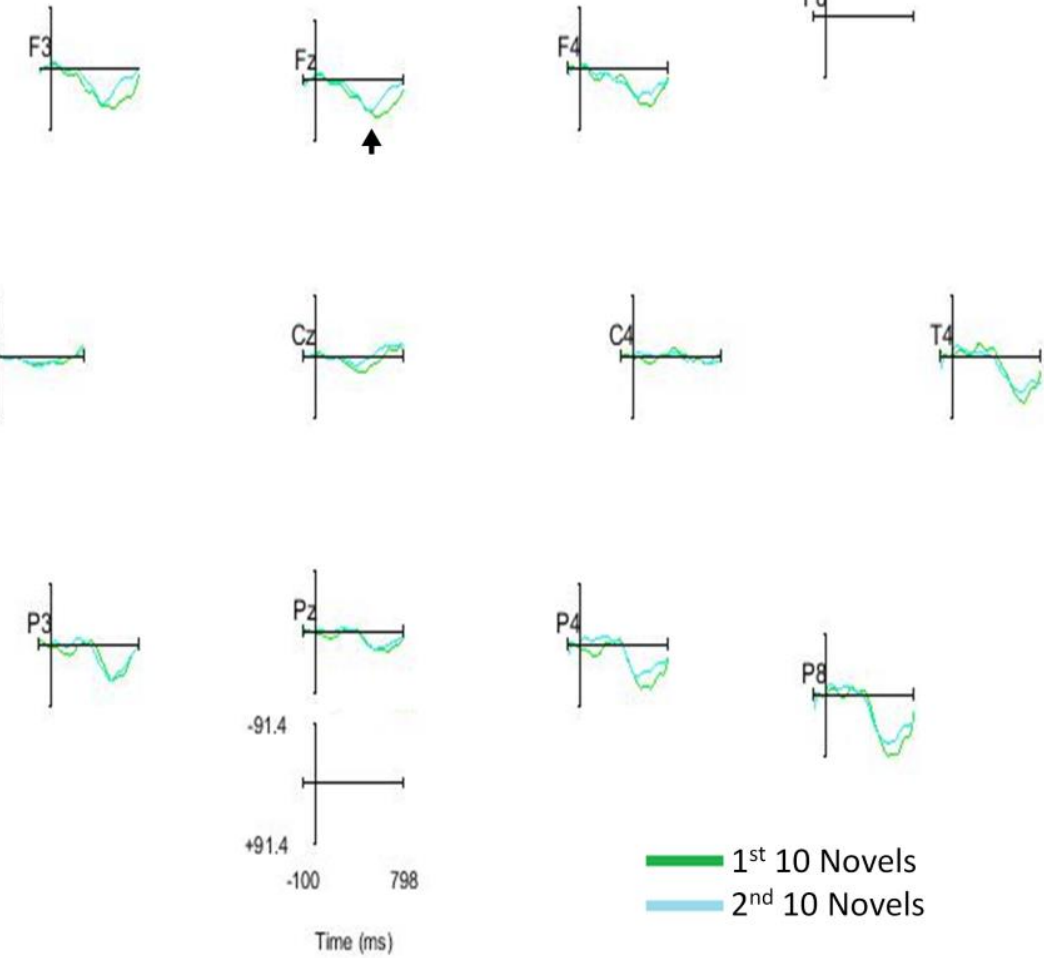
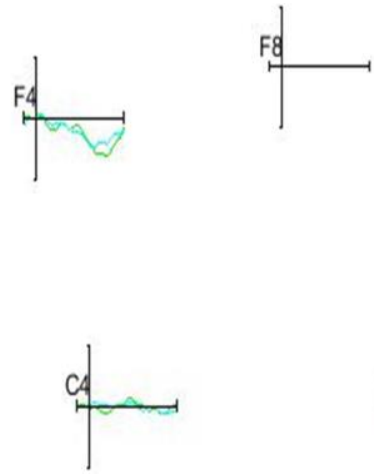

$1^{\text {st }} 10$ Novels $2^{\text {nd }} 10$ Novels

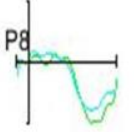


Fig s 9
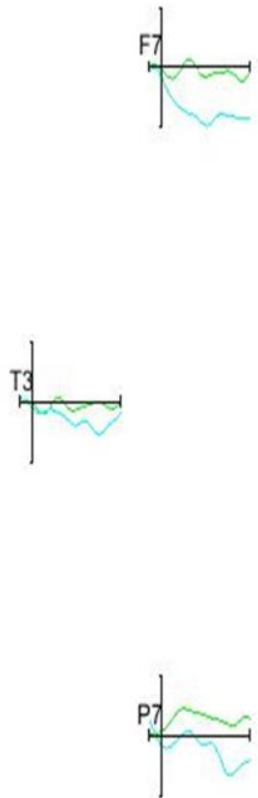

NOVELTY ERP SINGLE SUBJECT (PATIENT)
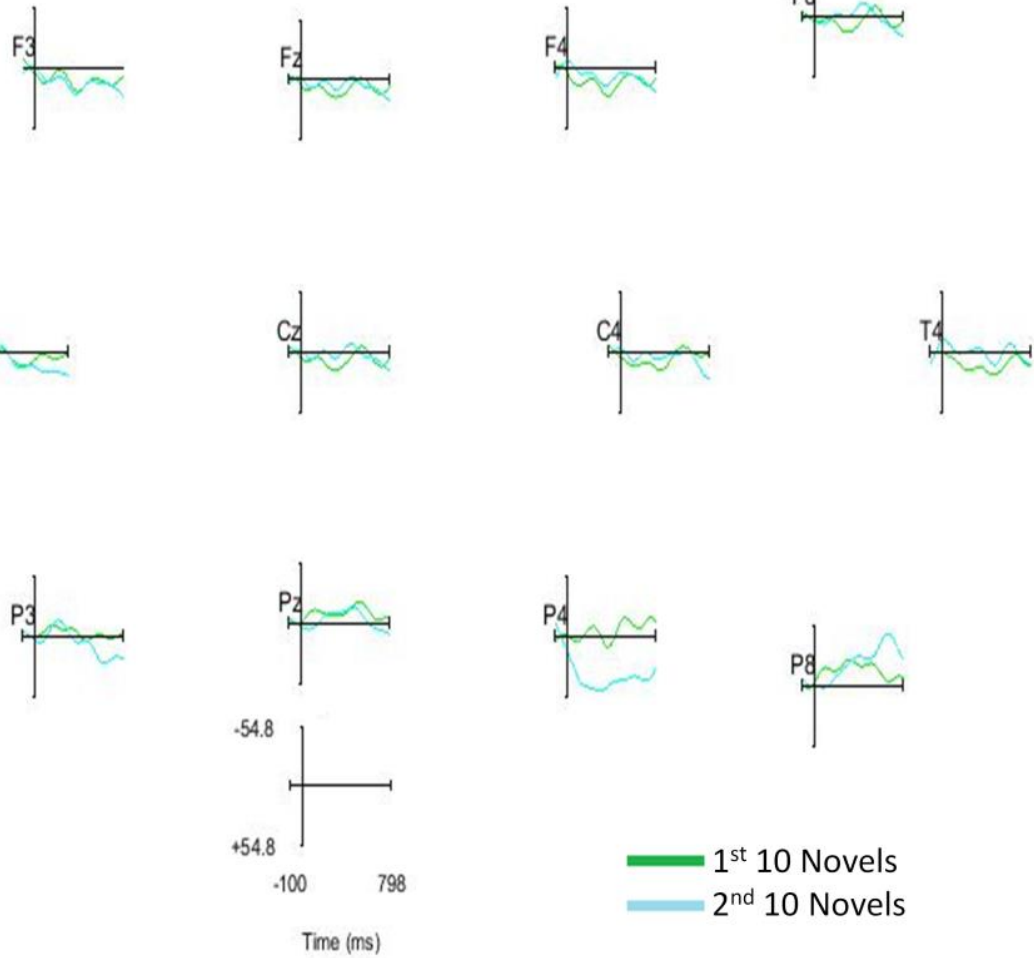

$1^{\text {st }} 10$ Novels $2^{\text {nd }} 10$ Novels 
Fig s10
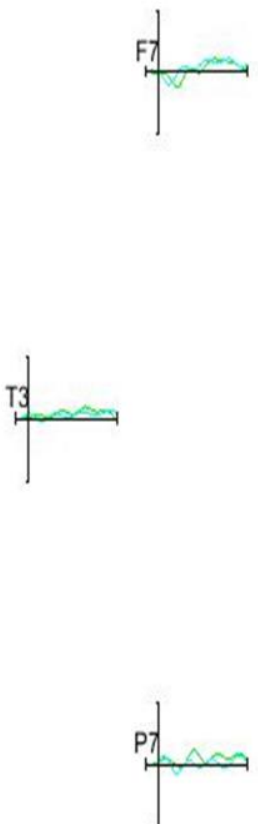

NOVELTY ERP SINGLE SUBJECT (PATIENT)
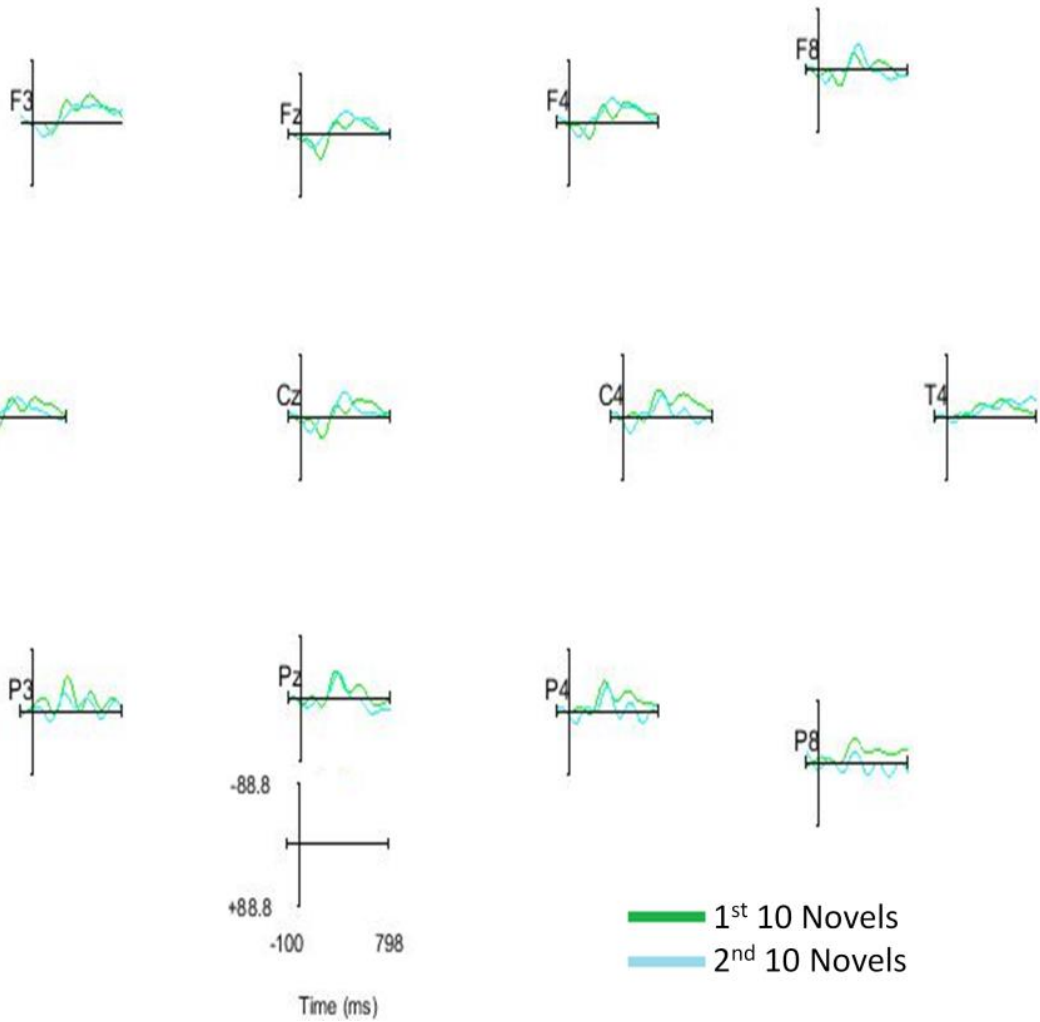

$1^{\text {st }} 10$ Novels $2^{\text {nd }} 10$ Novels 
Fig s11 TONE MISMATCH EXPERIMENT SINGLE SUBJECT (CONTROL)
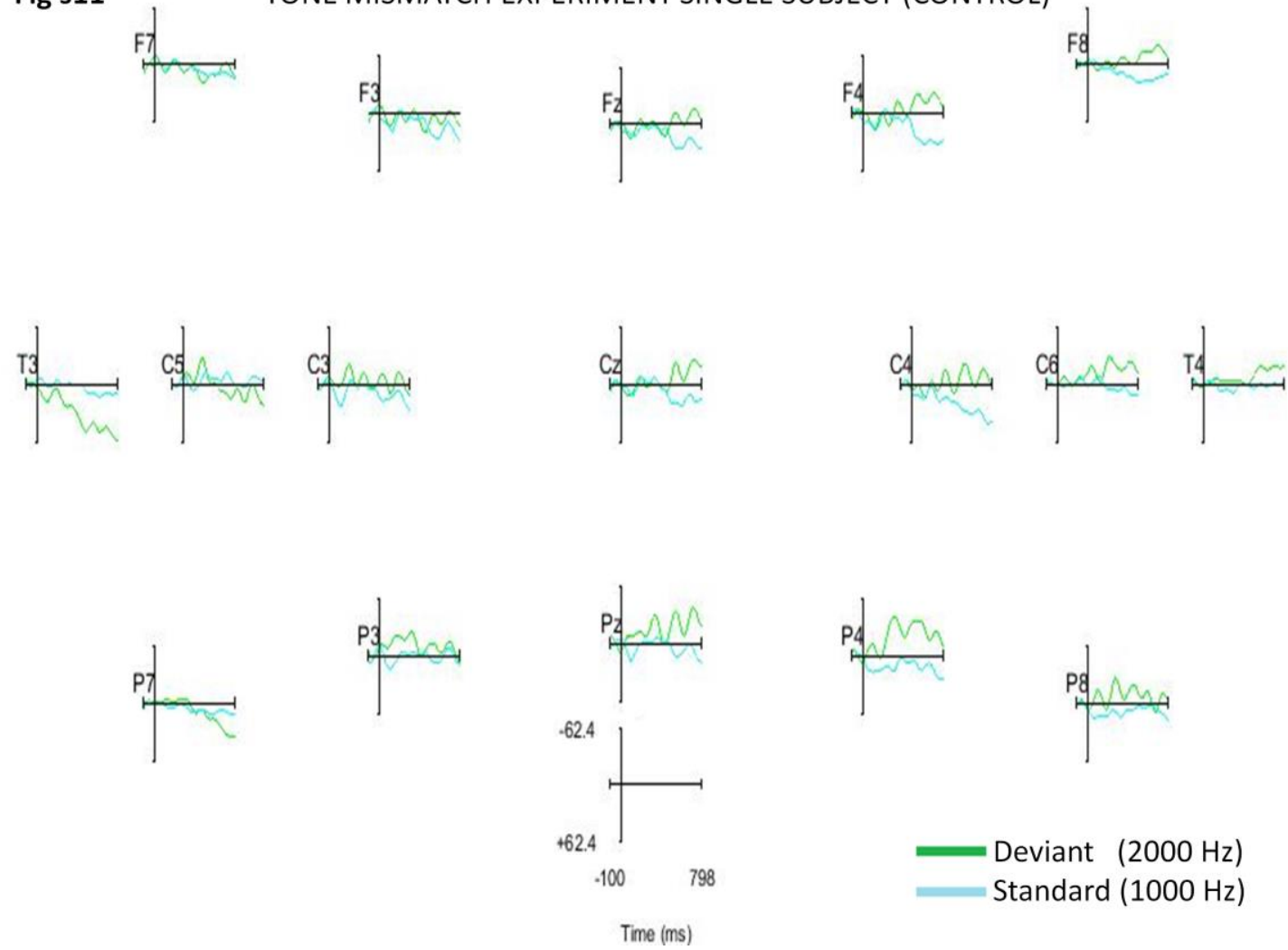
Fig $\mathbf{s 1 2}$

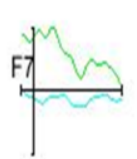

TONE MISMATCH EXPERIMENT SINGLE SUBJECT (PATIENT)
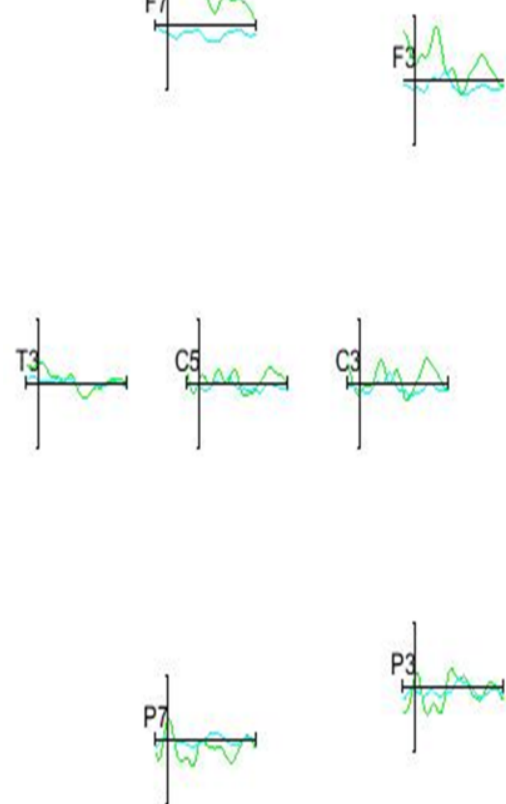
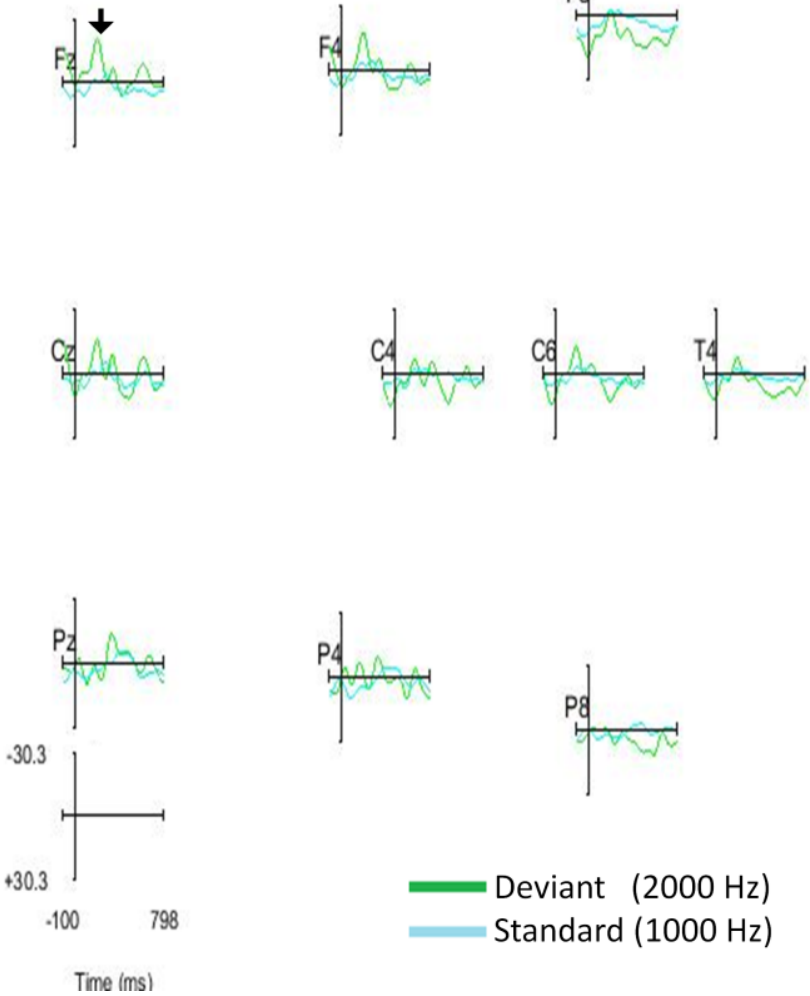

Deviant $(2000 \mathrm{~Hz})$

Standard $(1000 \mathrm{~Hz})$

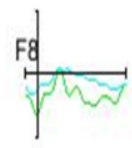


Fig $\mathbf{1 3}$

CONTROL GROUP GRAND AVERAGE

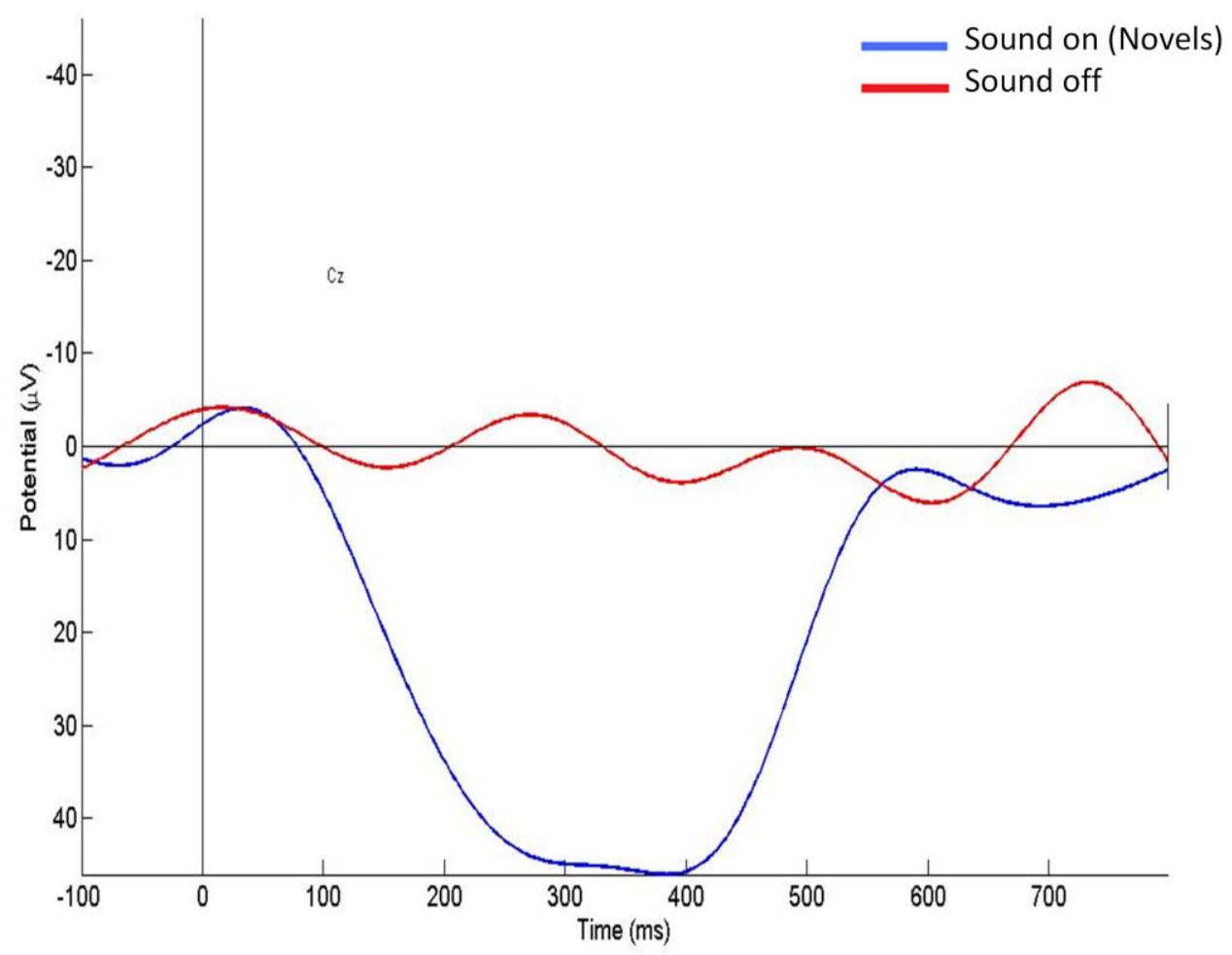


Fig s14

CONTROL GROUP GRAND AVERAGE

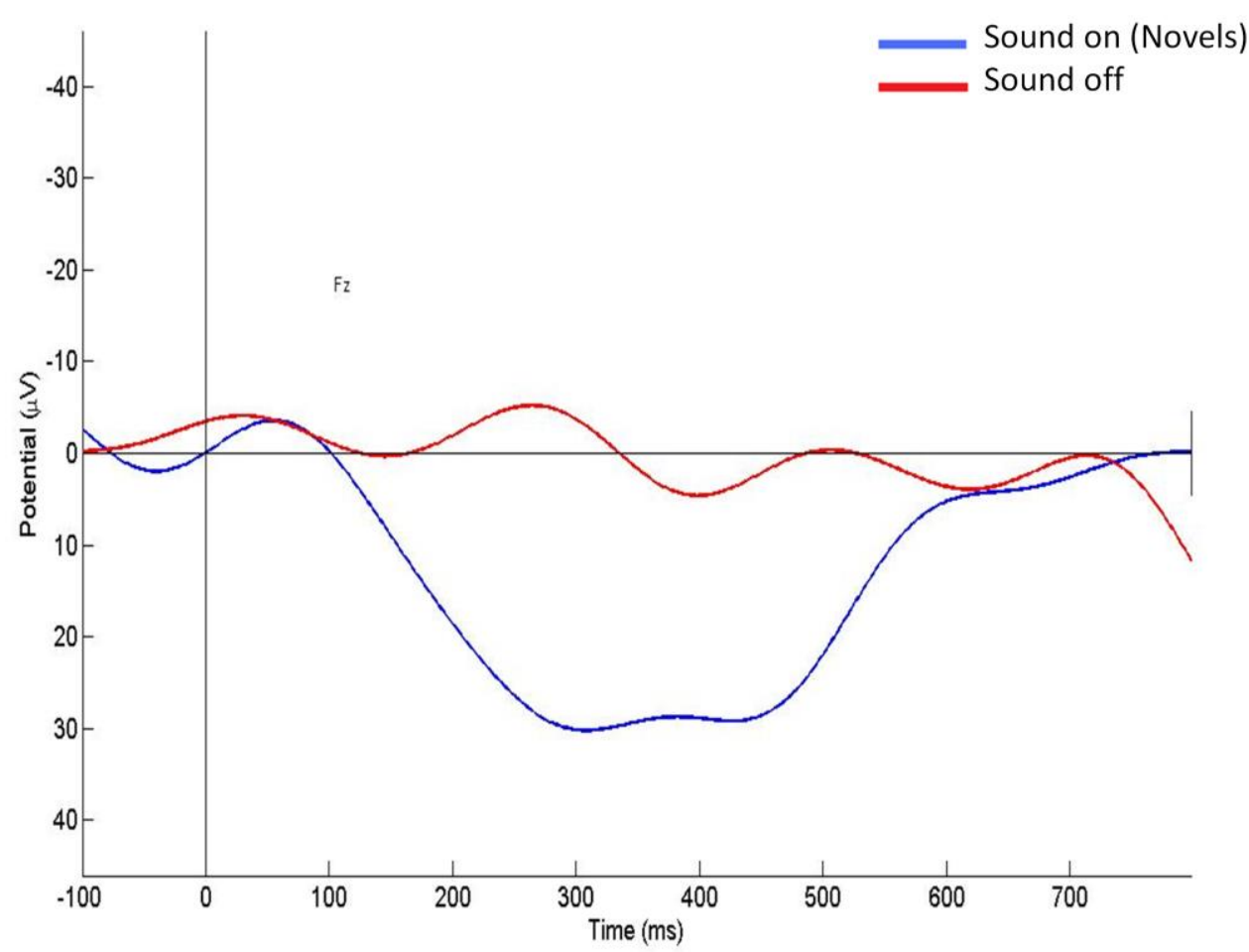


Fig s15

PATIENT GROUP GRAND AVERAGE

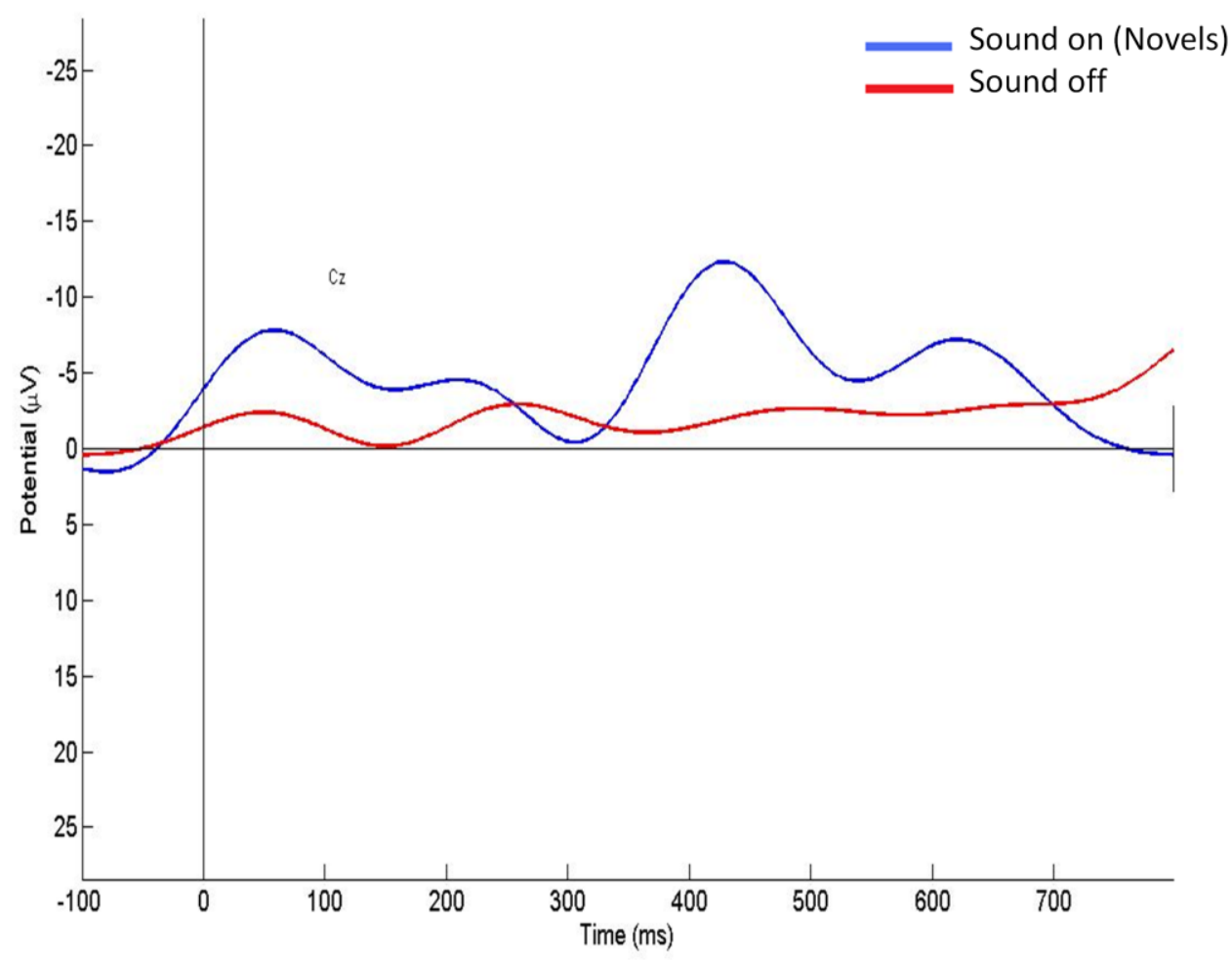


Fig s16

PATIENT GROUP GRAND AVERAGE

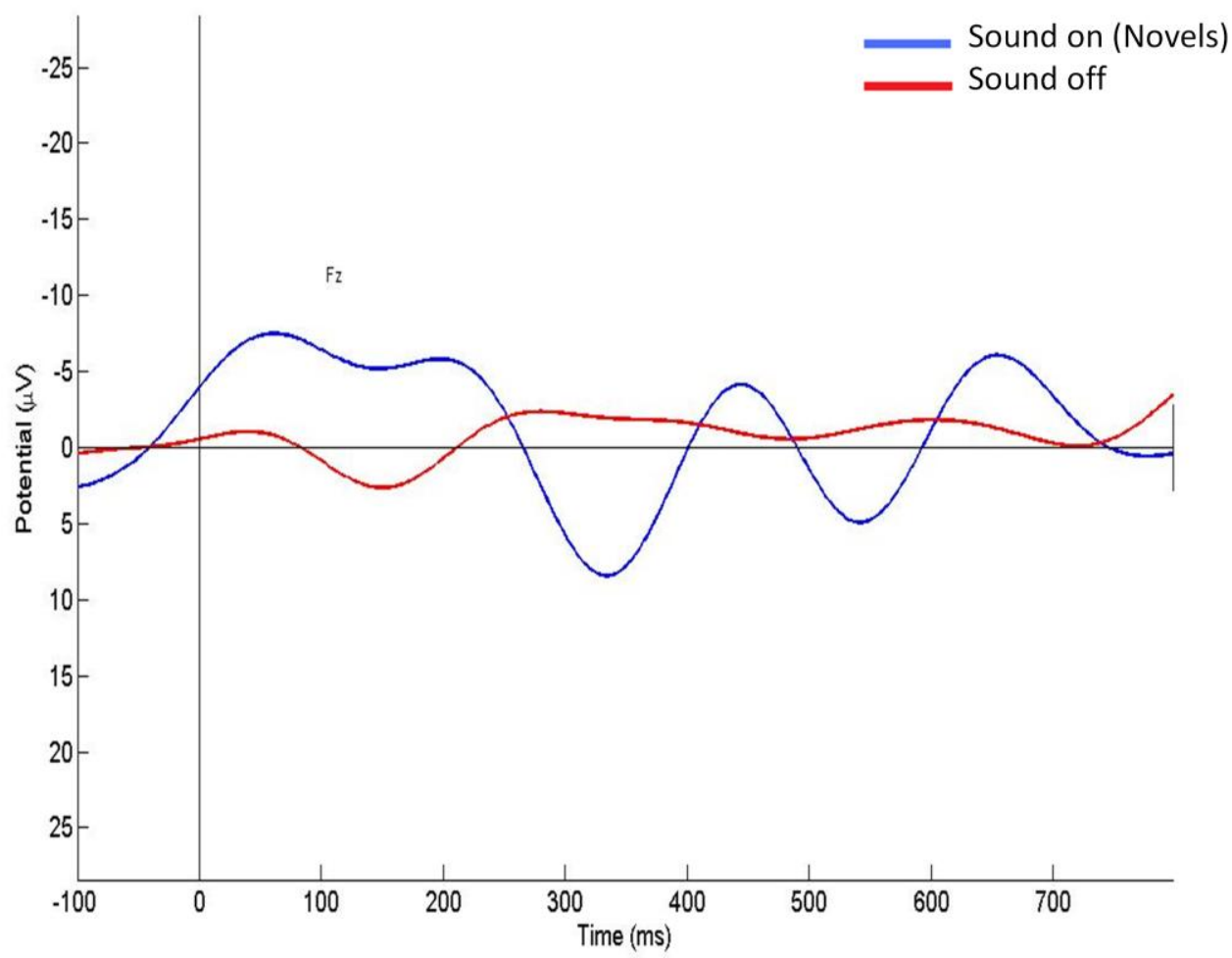

